\title{
Alzheimer's disease as a chronic maladaptive polyamine stress response
}

\author{
Review
}

\begin{abstract}
Baruh Polis ${ }^{1}$, David Karasik ${ }^{2,3}$, Abraham O. Samson ${ }^{1}$
1 Drug Discovery Laboratory, The Azrieli Faculty of Medicine, Bar-llan University, Safed, 1311502, Israel.

2 Hebrew SeniorLife, Hinda and Arthur Marcus Institute for Aging Research, Boston, MA, 02131, USA

3 Musculoskeletal Genetics Laboratory, The Azrieli Faculty of Medicine, Bar-Ilan University, Safed, 1311502, Israel.

Correspondence to Baruh Polis baruhpolis@gmail.com
\end{abstract}

Keywords: polyamines; arginase; senescence; aging; neurodegeneration. 


\section{Abstract}

Polyamines are nitrogen-rich polycationic ubiquitous bioactive molecules with diverse evolutionary-conserved functions. Their activity interferes with numerous genes' expression resulting in cell proliferation and signaling modulation.

The intracellular levels of polyamines are precisely controlled by evolutionary-conserved machinery. Their transient synthesis is induced by heat stress, radiation, and other traumatic stimuli in a process termed the polyamine stress response (PSR).

Notably, polyamine levels decline gradually with age; and external supplementation improves lifespan in model organisms. This corresponds to cytoprotective and reactive oxygen species scavenging properties of polyamines. Paradoxically, age-associated neurodegenerative disorders are characterized by an upsurge in polyamine levels, indicating polyamine pleiotropic, adaptive, and pathogenic roles. Specifically, arginase overactivation and arginine brain deprivation have been shown to play an important role in Alzheimer's disease (AD) pathogenesis.

Here, we assert that a universal short-term PSR associated with acute stimuli is beneficial for survival. However, it becomes detrimental and maladaptive following chronic noxious stimuli, especially in an aging organism. Furthermore, we regard cellular senescence as an adaptive response to stress and suggest that PSR plays a central role in age-related neurodegenerative diseases' pathogenesis.

Our perspective on $A D$ proposes an inclusive reassessment of the causal relationships between the classical hallmarks and clinical manifestation. Consequently, we offer a novel treatment strategy predicated upon this view and suggest fine-tuning of arginase activity with natural inhibitors to preclude or halt the development of AD-related dementia. 


\section{Contents}

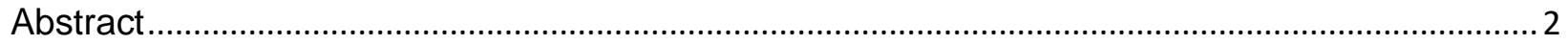

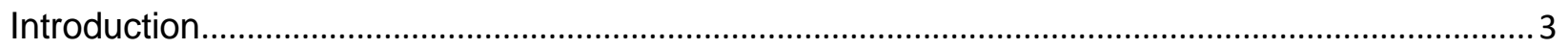

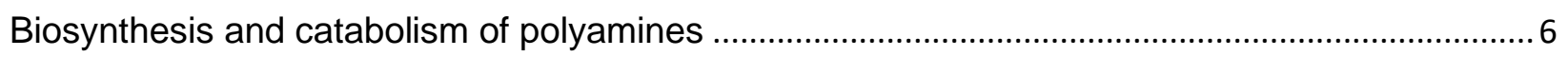

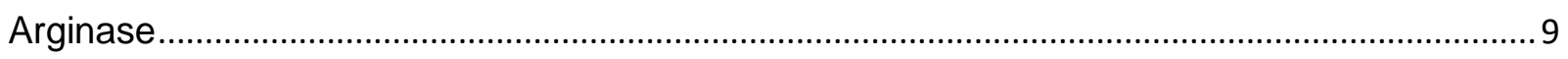

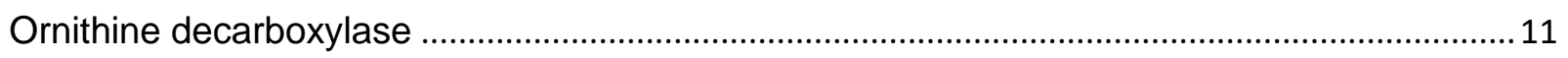

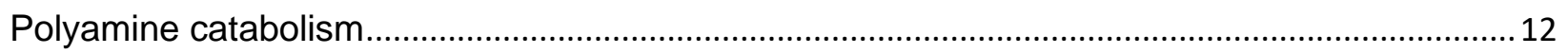

General biological functions of polyamines (with focus on CNS) …...........................................13

Polyamines' role in the brain development and neurogenesis.......................................................17

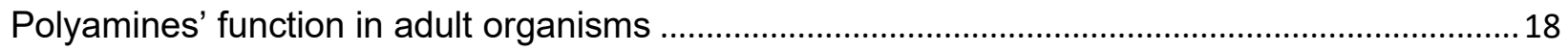

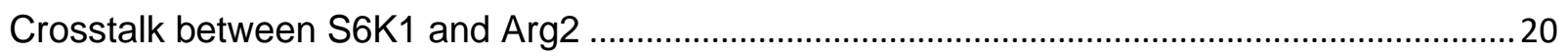

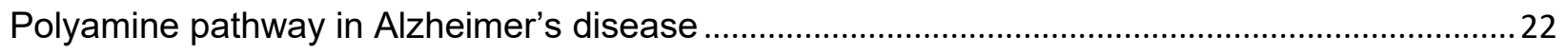

Evolutionary perspective on aging and Alzheimer's disease .....................................................30

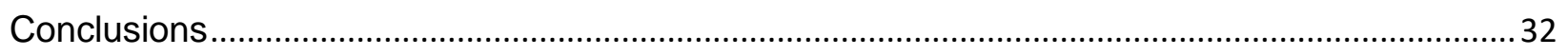

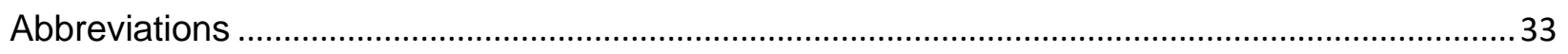

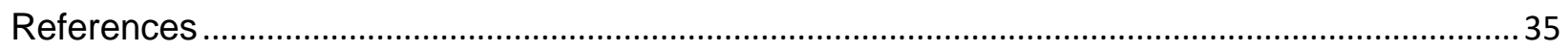

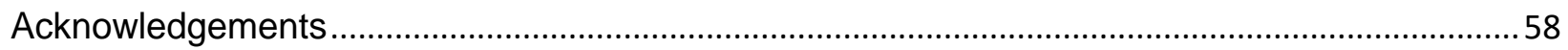

\section{Introduction}

Throughout their existence, organisms are repeatedly exposed to various stresses and thus have evolved species-specific strategies to effectively resist them and improve survival. Drought, starvation, heat, and cold shocks are among the universal stressful stimuli, which living creatures encounter during their life cycle. In addition, the organisms utilizing aerobic respiration or photosynthesis to produce energy continually deal with numerous oxidative challenges related to reactive oxygen and nitrogen species. Remarkably, similar to starvation and heat shock, oxidative stress induces polyamine synthesis in various species (1).

Polyamines are omnipresent primordial polycationic bioactive molecules possessing multifarious evolutionary-conserved biochemical functions. They are found ubiquitously at much higher concentrations than most other cellular metabolites (2). The polyamine, spermidine, was presumably present in the last universal common ancestor (LUCA). Other polyamines are essential for growth and biofilm formation in simple bacteria (3). 
Some bacteria produce diamines as a response to acid stress, via decarboxylation of arginine, ornithine, and lysine (4). In plants, polyamines are omnipresent and protective in stressful events such as sudden drought and extreme salinization (5).

In mammals, polyamines are universal regulators of basal cellular functions. The natural polyamines spermidine and spermine, their diamine precursor putrescine, together with diamine cadaverine, are aliphatic molecules (Fig. 1). They carry several nitrogen moieties, which are positively charged under physiological conditions. This feature provides them with an ability to interact with negatively charged nucleic acids and various proteins and influence critical cell functions via regulation of transcription, translation, and posttranslational modifications of a wide range of genes and proteins.

The levels and activity of enzymes involved in polyamines' biosynthesis and metabolism are regulated by various specialized and unconventional mechanisms at numerous levels. Their transcription, translation, posttranslational modification, and finally, degradation processes, comprise complex feedback mechanisms monitoring the substrates and products concentrations (6). These mechanisms are highly conserved in different species, which points to a central role of polyamines' function in all known life forms. Even though polyamines are universal primordial life elements, substantial gaps in the understanding of their precise physiological roles still exist. Moreover, polyamines' role in the pathogenesis of neurodegenerative diseases has received particularly scant scientific attention.

Recent discoveries have revealed many indispensable polyamines' biological functions and attracted weighty attention to their evolutionary role in health and disease. In adult organisms, numerous stimuli have been shown to alter polyamine homeostasis and elicit a highly concerted polyamine stress response (PSR) (7). Accruing evidence suggests that these alterations are adaptive and beneficial when they follow a moderate temporary stimulus, while tenacious stress leads to a maladaptive polyamine response, which contributes to malfunction and, eventually, degeneration. This maladaptive response characterizes pathogenesis of neurodegenerative disorders with typical arginase upregulation, arginine brain deprivation, and substantial increase in the brain levels of polyamines (8-11). 
<smiles>N=C(N)NCCC[C@H](N)C(=O)O</smiles>

Arginine<smiles>NCCCCN</smiles>

Putrescine<smiles>NCCCC[C@H](N)C(=O)O</smiles>

Lysine<smiles>NCCCCCN</smiles>

Cadaverine<smiles>NCCCCNCCCS</smiles><smiles>NCCCNCCCCNCCCN</smiles>

Fig. 1 Polyamine chemical structure. Shown are the chemical structure of the polyamine precursors amino acids L-arginine and L-lysine; and polyamines: putrescine, spermidine, spermine, and cadaverine.

Consequently, we postulate that polyamines function as universal bivalent regulators of cellular functions, which either promote growth of cells or induce their death depending on environmental signals. This view is in line with the recent hypotheses suggesting that natural polyamines are beneficial for the physiological processes in healthy cells, but excessively detrimental under some pathological conditions (12) hence activating senescence as an adaptive response to stress $(13,14)$. Accordingly, we regard cell senescence as a complex stress response phenotype contributing to neurodegeneration and progressive neuronal loss $(15,16)$.

Remarkably, polyamines-related adaptive response share some similarities with the prokaryotic stringent response and the eukaryotic unfolded protein response (UPR) (1). The former is a ubiquitous bacteria and chloroplast (plant organelle) stress response to 
starvation, heat shock, and other stimuli. The latter is related to the endoplasmic reticulum (ER) stress and is a common response within yeast, worms, and mammals. Therefore, PSR is one of the earliest mechanisms that, along with other mechanisms, cope with stresses and improve survival.

Gllad \& Gilad (2003) have proposed a model where the brain PSR is a component of the coordinated cellular stress program (17). Here, we further develop this hypothesis and propose an original model that throws light on the pathogenesis of age-associated neurodegenerative diseases, and of Alzheimer's disease (AD), in particular. We also describe a novel treatment strategy predicated upon this view and suggest fine-tuning of arginase activity with natural inhibitors in order to preclude or halt the development of clinical dementia, and perhaps even delay aging.

\section{Biosynthesis and catabolism of polyamines}

Polyamine metabolism has been reviewed in detail by several authors. The interested reader is referred to an excellent review by Wallace et al. (18). Here, we cover a topic that has received a relatively limited scientific attention and underline the role of enzymes that have been shown to play a role in the pathogenesis of neurodegenerative disorders.

The cellular levels of polyamines in various tissues are congruous with their physiological requirements. This is achieved by a joint function of synthesis, catabolism, and transport. The chief biosynthetic polyamines' pathway in mammals utilizes arginine as a precursor of putrescine and comprises arginase and ornithine decarboxylase (ODC) or, alternatively, arginine decarboxylase (ADC), and agmatinase (AGM) (Fig. 2).

The polyamine, cadaverine, produced via lysine decarboxylation, is much less abundant in mammal species. Cadaverine is a precursor of piperidine, which efficiently accumulates against concentration gradient in the murine brain (19). Significant amounts of cadaverine are formed and resorbed in the intestine; however, endogenous sources of cadaverine in the mouse brain had been evidenced too (20) and suggested to be responsible for some central nervous system (CNS) functions (21). In addition, cadaverine can be utilized by the gut Escherichia coli in an alternative pathway to produce putrescine (22). 
The biosynthesis of polyamines is an evolutionary-conserved and ubiquitous metabolic pathway. In all life forms, putrescine is the most common diamine. Most eukaryotes produce putrescine via decarboxylation of ornithine. There is an indirect putrescine biosynthesis pathway from arginine, which involves ADC (23). The product of the reaction, agmatine, may be converted to putrescine by AGM (Fig. 2).

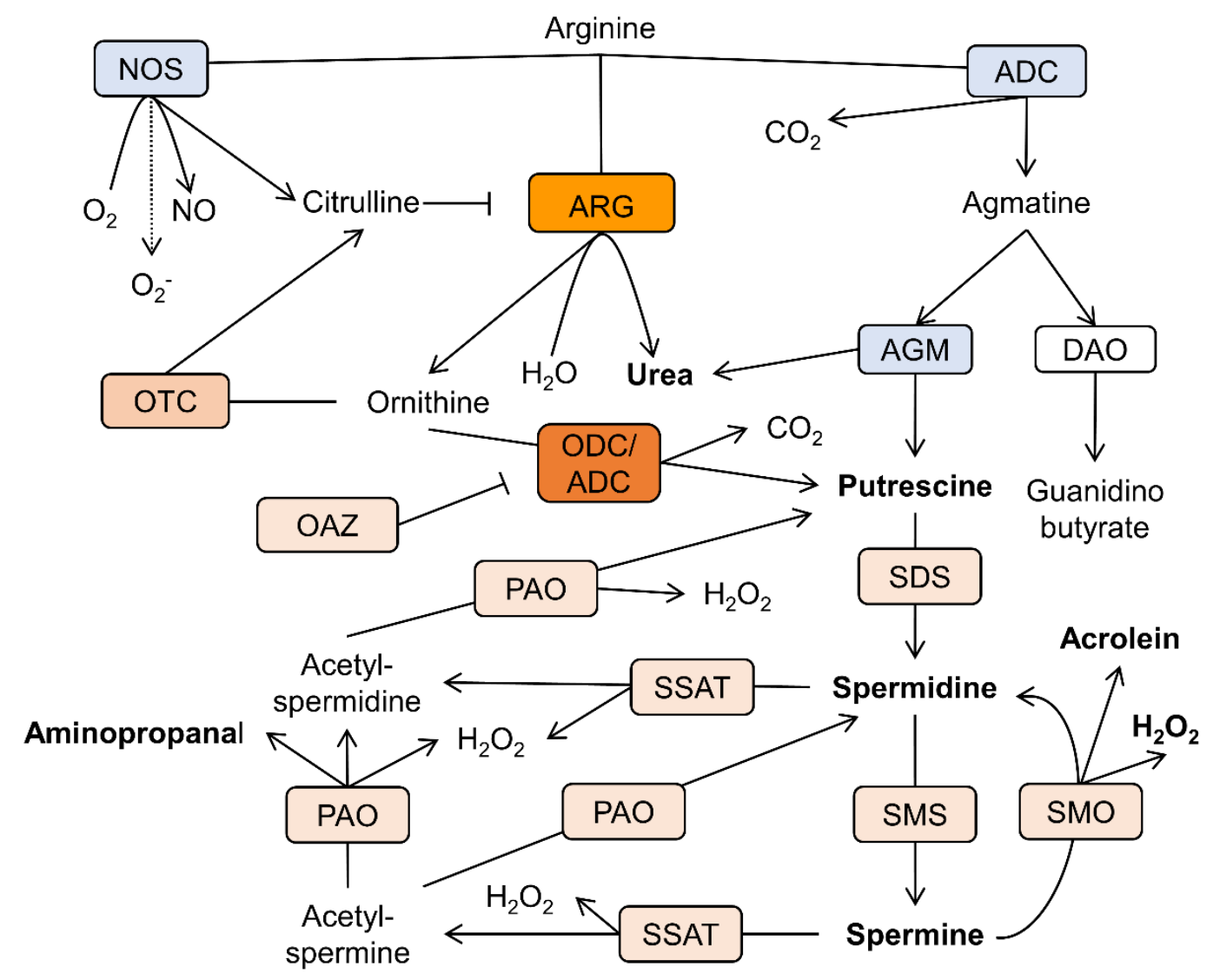

Fig. 2 Schematic representation of the polyamine metabolism pathways in AD brain. Arginine is the mutual substrate for arginase (ARG), arginine decarboxylase (ADC), and nitric oxide synthase (NOS). Ornithine decarboxylase (ODC) decarboxylases ornithine to produce putrescine. Spermidine/spermine acetyltransferase (SSAT) catalyzes the acetyl-group transfer from acetyl-coenzyme $A$ to the aminopropyl end of spermidine or spermine, producing acetylspermidine and acetylspermine. Acetylated polyamines are oxidized by polyamine oxidase (PAO) to produce hydrogen peroxide $\left(\mathrm{H}_{2} \mathrm{O}_{2}\right)$, aminopropanal, and either putrescine or spermidine. Otherwise, spermine can be directly oxidized to spermidine by spermine oxidase (SMO) generating $\mathrm{H}_{2} \mathrm{O}_{2}$ and aminopropanal, which is spontaneously converted to acrolein. Other abbreviations: ornithine transcarbamylase (OTC), agmatinase (AGM), ODC antizyme (OAZ), 
spermidine synthase (SDS), spermine synthase (SMS), diamine oxidase (DAO). Rectangles' color reflects the level of enzymes' expression in relation to the healthy brain. Rectangles' color reflects the level of enzymes' expression in relation to the $A D$ and the aging brain. Blue-reduction, shades of orange- increase in levels (arbitrary scale).

In accordance with the dominant view, ODC is the limiting factor of the polyamines' biosynthesis in mammals (6). However, recent attention has been turned to arginase and $A D C$ as putative gate keepers of polyamine synthesis. Agmatine has been recognized long ago as an ADC product in primitive life forms; nevertheless, ADC expression in mammals was doubted. Li et al. (1994) investigated the bovine brain and provided conclusive evidence that agmatine is an endogenous imidazoline receptors agonist. The authors demonstrated that agmatine is a locally synthesized noncatecholamine ligand of a2-adrenergic receptors that acts as a neurotransmitter (24) (Fig. 3). Of note, both glia and mature neurons demonstrate ADC activity (25). ADC activity has been identified in other organs and various cell types (26). Several groups recurrently demonstrated the presence of mammalian ADC in rodents and humans $(25,27)$. Moreover, it has been proven that $A D C$ gene is responsible for the production of agmatine in the brain (25). Additionally, it was revealed that ADC is associated with mitochondrial membranes and capable of decarboxylating both arginine and ornithine (28). Remarkably, the brain ADC possesses a higher affinity for ornithine than for arginine (27) (Fig. 2). Accordingly, in the cases of the mutual substrate (arginine) deficiency and relative ornithine excess, due to arginase upregulation for instance, ADC acts together with ODC to produce putrescine, which leads to a substantial decrease in the brain agmatine content.

Of note, agmatine demonstrates a broad spectrum of pharmacological actions in mammals, which include anti-nociceptive (29) and anti-inflammatory effects (30). Likewise, it protects neurons against glutamate-induced cytotoxicity in vitro (31) and ischemic neuronal injury in vivo (32) (Fig. 3). Therefore, its deficit may have serious effects on brain function, particularly in the conditions of oxidative stress.

Curiously, despite extensive literature, there are still papers suggesting that agmatine is synthesized exclusively by plants and bacteria, but not by mammals (12). This proposition is indefensible. Moreover, mammalian ADC is unique and substantially distinct from ODC 
and ADC enzyme of bacteria and plants (27). In prominent opposition to other polyamine pathway enzymes, ADC and arginase are both constitutively active enzymes, which are indispensable for polyamine synthesis, and are extensively expressed in the mammal brain. The cortical and hippocampal principal cells and interneurons clearly express both of them (33).

\section{Arginase}

Remarkably, the minimal enzymatic content of the LUCA already included representatives of the arginase superfamily (34), pointing to their significance for the perpetuation of life. Arginase is a particularly interesting enzyme that has been present in early life forms and conserved throughout evolution. It is a manganese metalloenzyme catalyzing the hydrolysis of arginine to ornithine and urea in the last step of the urea cycle (35) (Fig. 2). Two distinct genetic isoforms of human arginase, arginase-1 (Arg1) and arginase-2 (Arg2), share 59.4\% of amino acids sequence (33)(36). Structurally, both isoenzymes are homotrimers stabilized in conformation by two $\mathrm{Mn}^{2+}$ ions per each monomer (37).

Of note, the duplication of the arginase coding gene is a relatively recent evolutionary event, which occurred following the separation of vertebrates and invertebrates (38). Simple organisms, such as plants, bacteria, and yeasts, possess a single form of Arg2 situated in the mitochondria. Mitochondrial localization of Arg2 indicates its evolutionary roots in bacteria (39). Vertebrates additionally express a cytosolic isoform, Arg1 (35). Therefore, it is presumed that the mitochondrial arginase is the ancestral isoform (40).

In mammals, both arginase isoforms show distinctive cell and tissue distribution patterns. They are encoded by genes in separate chromosomes; however, their mechanism of action and products are similar. Arg1 is generally presented as a cytosolic enzyme of the liver and is very common in other tissues including the brain. Arg2, in contrast, is described as a kidney-type mitochonrial enzyme; however, its expression has been shown in the mitochondria of various organs including the brain tissue $(11,41)$.

The chief function of arginase in ureotelic animals, being the last enzyme of the urea cycle, is to deal with excess of ammonia (42) (Fig.2). However, recent discoveries indicate the enzyme's role in diverse physiological functions and pathological processes that are 
far beyond the urea cycle. The presence of both isoforms in the murine brain tissue, and particularly in the hippocampal neurons, has been proven by several groups $(11,43)$. There are estimations that arginase brain activity is equally accounted for by both isoforms $(40,44)$, though $\operatorname{Arg} 2$ has been shown to be a dominant isoenzyme in the human frontal cortex (45).

Of importance, the levels of two central urea cycle enzymes, namely ornithine transcarbamylase (OTC) and carbamoyl phosphate synthetase 1 (CPS1), in the healthy mammal brain are extremely low (46), which points to a unique function of arginase in the CNS.

Typically, the expression of arginase is inducible by a variety of cytokines and catecholamines. It has been shown that 5 ' flanking region of Arg1 gene contains elements responsive to interleukin-4, cAMP, tumor growth factor $\beta$, dexamethasone, and lipopolysaccharides (LPS) (47). Oxidative species also instigate Arg1 expression and stimulate its activity via Protein kinase C-mediated activation of RhoA/Rho kinase pathway (48).

Arg2 levels in endothelial cells escalate as a reaction to numerous stimuli as well, including bacterial LPS, tumor necrosis factor alpha (TNFa), oxidized low-density lipoproteins (LDL), and hypoxia (49). Remarkably, Arg2 activation in the endothelial cells is associated with its translocation from the mitochondria to the cytosol (50). A similar pattern has been reported in the hippocampal neurons of $A D$ mice (11). It is wellestablished that AD-associated conditions with elevated ROS result in mitochondrial swelling, outer membrane rupture, and the cell death induction (51). Therefore, the presence of Arg2 in the cytoplasm may be explained by the disease-associated severe mitochondrial damage (Fig. 4).

Of importance, arginase inhibition also reduces the production of interleukin-8 in vascular endothelial and smooth muscle cells as a reaction to native low-density lipoprotein (LDL) (52). Moreover, the mitochondrial membrane potential (MMP), which is generally decreased upon native LDL stimulation, is restored upon arginase inhibition. Thus, inhibition of arginase has been proposed to treat a list of cardiovascular diseases (53). 
Growing evidence suggests a role that arginase plays in the pathogenesis of neurodegenerative diseases (54). The activity and expression levels of arginase are significantly higher in the hippocampi of AD patients and AD mice (11)(55). Moreover, substantially reduced levels of arginase substrate, arginine, are observed in the cortices of AD patients (56). The intriguing question of how Arg1 and Arg2 differ in their biological function and regulation under various pathological conditions remains an area of intensive research.

\section{Ornithine decarboxylase}

$\mathrm{ODC}$ is the rate-limiting enzyme for polyamine synthesis that decarboxylates ornithine to form putrescine (Fig. 2). The adult brain contains substantial amounts of ODC protein, but its enzymatic activity is relatively low in the healthy adult brain. In contrast to other metabolic pathways, a family of specific antizymes inhibits ODC, and regulates polyamine transport (57). ODC antizyme (OAZ) is a natural ODC inhibitor (Fig. 2). Its binding to ODC also causes fast degradation of the enzyme (58).

Remarkably, OAZ is firmly preserved over evolution; however, its detailed function is poorly understood. The OAZ expression is promoted by high cellular polyamines' concentration, perhaps as a feedback mechanism to limit polyamine modulation of $\mathrm{N}$ methyl-D-aspartate receptors (NMDAR), and the adult brain shows a relatively high expression of OAZ (59). In the brain, the antizyme typically co-localizes with NMDARs of the cortical pyramidal cells $(60)$, which indicates its role in regulating channel functions.

Of note, a substantial accretion of OAZ in the brains of AD patients compared to healthy individuals has been reported. Remarkably, in these cases, OAZ preferentially accumulates in the neuronal bodies and axons of the hippocampus. Thus, it was proposed that $A D$-related $O A Z$ accumulation possesses neuroprotective functions (60). It is plausible to hypothesize that the upsurge in antizyme levels in the AD brains reflects the natural mechanism of reduction the polyamine pathway overactivation-associated toxicity, as well as NMDAR modulation, which is inadequate in the conditions of chronic PSR.

Of importance, $A D$-associated ODC translocation from nucleus to cytoplasm in the pyramidal cortical cells has been reported (61). Nilsson et al. elegantly evidenced an early 
shift of the ODC immunoreactivity from the nuclear compartment towards the cytoplasm in $A D$ brains. This pattern of expression resembles the mentioned above translocation of Arg2 to the cytoplasm. Accordingly, we suggest that these characteristic translocation phenomena indicate AD-related changes in polyamine metabolism dependent upon subcellular localization of its principal enzymes (Fig. 4).

\section{Polyamine catabolism}

Spermidine/spermine acetyltransferase (SSAT) is the rate-limiting polyamine catabolism enzyme that acetylates polyamines and converts them to functionally inactive forms due to alteration in charge (Fig. 2) (62). Additionally, spermidine and spermine acetylation facilitate their degradation and excretion. Of note, their efflux is coupled to arginine uptake, indicating the interplay between polyamines catabolism and anabolism (63). Many factors are capable of inducing the polyamine catabolism. Polyamines, corticosteroids, estradiol, growth hormone, non-steroidal anti-inflammatory drugs instigate SSAT levels and activity (64).

Polyamine oxidase (PAO) oxidizes acetylspermine and acetylspermidine to form spermidine and putrescine respectively, together with aminopropanal and hydrogen peroxide. Additionally, spermine is oxidized by spermine oxidase (SMO) to produce hydrogen peroxide, and acrolein (Fig. 2) that exert numerous cytotoxic, mutagenic, and immunosuppressive effects $(65,66)$. Of importance, the levels of protein-conjugated acrolein are substantially elevated at the infarction locus in a rodent model of stroke (67). Moreover, the infarction dimensions are significantly decreased following the application of $\mathrm{N}$-acetylcysteine, which is an efficient acrolein scavenger, indicating acrolein pathogenic role.

Remarkably, acrolein levels are significantly increased in AD patients' hippocampi (68). Additionally, acrolein adducts are present in dystrophic neurites surrounding senile plaques (69). Accordingly, acrolein's role in the AD pathogenesis has been suggested (70). Moreover, proved neurotoxicity of the polyamine degradation products such as hydrogen peroxide, acrolein, and aminopropanal, led to the "aldehyde load" hypothesis of neurodegenerative disorders $(71,72)$. 


\section{General biological functions of polyamines (with focus on CNS)}

We have mentioned that polyamines carry positively charged nitrogen moieties. DNA is typically negatively charged polymer due to the presence of negatively charged phosphate ions in the sugar-phosphate backbone. In his pioneering work, Tsuboi Masamichi (1964) reported that the distances between the charged entities of polyamines correspond well to the distances between DNA phosphates (73). The author proposed an original model of spermine interaction with the DNA molecule, which leads to stabilization of its double-helical conformation. More recent studies proved that large amounts of the intracellular polyamines are associated with DNA and RNA and capable of influencing the genes' transcription and translation rate (74,75). Muscari et al. (1995) demonstrated that spermine efficiently bounds to the DNA strands and exerts a potent antioxidative effect at physiological $(0.1 \mathrm{mM})$ concentration (76). Spermine has also been shown to scavenge free radicals and protect DNA from the ROS-associated damage (77).

Remarkably, polyamines demonstrate dissimilar effects on gene expression in relation to their concentration. They enhance gene expression at low concentrations but completely inhibit at high concentrations (78). Of note, the polyamines concentrations used in the study (78) are at physiological range $(0.1-2 \mathrm{mM})$. The authors speculate that polyamines provide favorable conditions for RNA polymerase to access DNA segments with a reduced negative charge. A similar pattern of concentration-dependent differential effects of polyamines on the initiation and elongation of protein synthesis has been reported by Giannakouros et al. in an original experiment in cell-free system (79). Accordingly, a dual role of polyamines in stress is related to their ability to turn on some stress-responsive genes but shut down other genes has been suggested (1).

Accumulating evidence points to polyamines-DNA interaction sequence specificity that overrides a simple electrostatic interaction. There are indications of preferential polyamines binding to TATA elements (80). Different binding modes of spermine to poly (dG-dC) in comparison with A-T containing polynucleotides have also been reported (81). Therefore, polyamines are capable of preferential activation or silencing of some genes in accordance with their nucleotide motifs. 
In relation to the CNS, polyamines show numerous physiological effects, which support normal neuronal function and axonal integrity. At functional level, polyamines modulate complex cognitive processes and facilitate associative memory acquisition and recall (82) (83). However, besides regulation of basal cellular functions, in the mammal brain polyamines subserve highly specific tasks. In neurons, they regulate gating of several ion channels. In some cases, the mechanism is very simple. Membrane depolarization attracts cytosolic polyamines into the channel pore, which prevents ion flow (84) (Fig.3). This mechanism may moderate overexcitation associated with acute trauma. Additionally, polyamines have been shown to confer inward rectification to certain potassium channels, a-amino-3-hydroxy-5-methyl-4-isoxazolepropionic acid (AMPA) receptors, and nicotinic acetylcholine receptors (nAChR). Intracellular spermine, particularly, is responsible for intrinsic gating and rectification of inward rectifier potassium channels by plugging the channel pore (85). Moreover, polyamines bind with high affinity to the omnipresent inwardly rectifying potassium channels. This process efficiently facilitates influx of potassium and affects electrolyte balance, resting membrane potential, and the cell electrical activity (86) (Fig.3).

Pioneering studies by Williams et al. (1989) suggested that NMDA receptor complex possesses a polyamine recognition site (87). Considering the NMDA receptor as the predominant molecular device for controlling synaptic plasticity and memory function at cellular level, polyamines appear to efficiently modulate human memory. Later works demonstrated multiple effects of extracellular spermine and evidenced polyamine binding to glutamate-sensitive NMDA, AMPA, and kainite receptors (85) (88).

Considering the complex effects of polyamines upon the neuronal activity via interaction with numerous ion channels it is explicable why the polyamines pathway is highly responsive to pathological brain conditions like trauma (7), stroke (89) and epilepsy (90), and plays a role in the pathogenesis of numerous mental disorders. Of note, substantial alterations in the levels of polyamines have been demonstrated in schizophrenia, mood disorders, anxiety and suicidal behavior $(91,92)$. Though, the direct causal relationship between the events is still debated in the literature. 
Of importance, various pathophysiological processes associated with neuronal damage have been shown to induce activation of putrescine synthesis. Dempsey et al. (1988) utilized bilateral carotid artery occlusion to produce dense forebrain ischemia and demonstrated enhanced levels of ODC in cortical neurons of ischemic gerbils (93). However, in this case, the authors propose that ODC is a causative factor or, at least, a marker, which is associated with metabolic events leading to progressive functional deterioration after cerebral ischemia. Paschen et al. (1991) used hypoglycemic coma in rats to induce significantly increased putrescine levels throughout the brain (94). The authors speculate that the increase in putrescine content is an early marker of neuronal cell necrosis regardless of the injury pathogenesis.

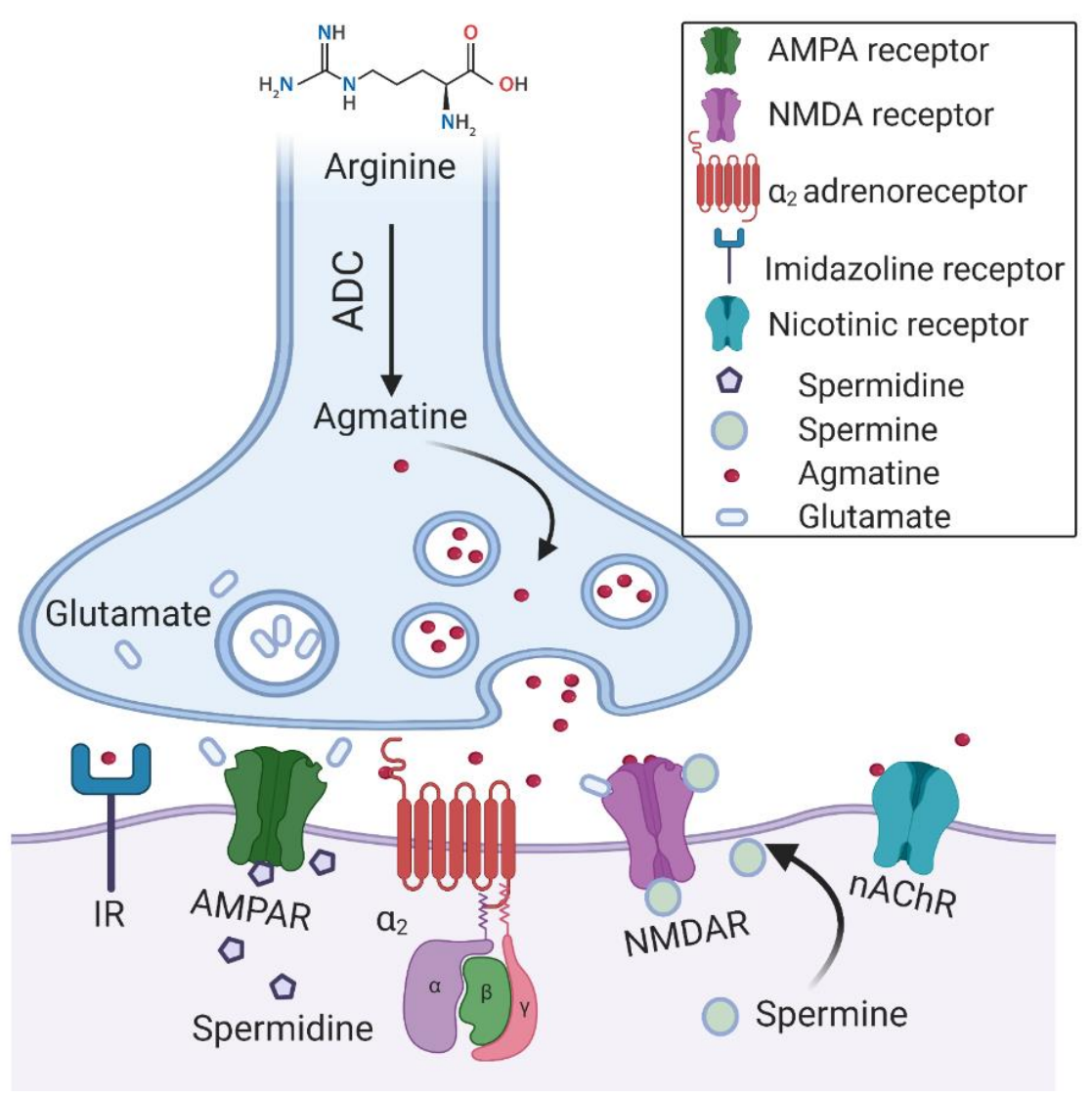

Fig.3 A hypothetical synapse diagram. Arginine decarboxylase (ADC) converts arginine into agmatine and carbon dioxide. Agmatine is a neurotransmitter that is synthesized, stored in vesicles, and released following depolarization. Agmatine binds with high affinity to a2adrenoceptors (a2) and imidazoline receptors (IR). It antagonizes glutamatergic NMDA, AMPA, and $n A C h$ receptors. Polyamines, spermine, and spermidine modulate the activation of NMDA 
receptors via a unique allosteric regulatory site at the extracellular domain. The pore of ionotropic glutamate receptors is easily accessible to cationic polyamines, which are capable of blocking the ions movement via the channels. Polyamines efficiently block ACh-induced currents via nAChR.

Sauer et al. (1992) occluded cerebral artery to induce ischemia in rats (95). The procedure led to elevation in the levels of putrescine in infarcted and non-infarcted areas. Remarkably, treatment with difluoromethylornithine (DFMO), an inhibitor of ODC, prevented the ischemia-induced increase in putrescine levels; though, it did not affect the infarct volume, which indicated polyamines function as protective rather than pathogenic. Subsequently, it has been proven in numerous models that the universally observed after acute neuronal damage ODC activation followed by putrescine accumulation are the means of cellular protective mechanisms (96-98).

Gilad \& Gilad (1992) pointed out that the capability of polyamines to modulate the ion channels functions may assume importance in cellular defense mechanisms (7). The authors revolutionarily proposed that neurotrauma-related induction of the inherently transient polyamine response is an integral part of protective biochemical programs that are vital for neuronal survival. Consequently, the authors further developed their model and suggested that the brain PSR, is a common reaction to stressful stimuli, including physical, emotional, and other stressors, with a magnitude directly correlated with the stress intensity (17). The researchers indicated that traumatic injury of extreme degree results in an incomplete PSR associated with accumulation of putrescine but reduction in the levels of the higher polyamines, spermidine and spermine.

This model explains the protective effects of the systemic polyamines application evident in forebrain neurons following acute ischemia (99). Direct application of polyamines has also been shown to be neuroprotective. For instance, L-arginyl-3,4-spermidine neuroprotective properties have been proven in several in vitro models of neurodegeneration and in vivo transient forebrain ischemia rat model (100).

Extracellularly applied arginase has been proven to be a potent neuroprotector and a nitric oxide-independent inhibitor of neuronal apoptosis (41). Moreover, upregulation of Arg1 leading to a substantial upsurge in spermidine synthesis has been shown to promote 
axonal regeneration (101). Accordingly, we suggest that Arg1 is an integral part of the brain adaptive PSR.

Recently, Dhara et al. elegantly demonstrated that polyamines control assembly of neuronal nicotinic $\alpha 4 \beta 2$ and $\alpha 7$ acetylcholine receptors (102). This capability is unique since polyamines do not modulate assembly of any other ion channels. This feature relies upon negatively charged residues within the receptors' cytosolic loop. Remarkably, lowering polyamine levels upregulates brain $\alpha 4 \beta 2$ and $\alpha 7$ levels. Moreover, the authors evidence strong correlation between increased acetylcholine-evoked currents and SSAT activity. Additionally, they show that SSAT promotes cell-surface expression and assembly of $n A C h R s$ by catalyzing polyamines. Strikingly, DFMO pretreatment leads to the same phenotype (102).

Of importance, $\alpha 4 \beta 2$ and $\alpha 7 A C h R$ are the most abundant $n A C h R$ in the brain that control various aspects of synaptic signaling and plasticity related to memory acquisition and recall (103). It seems that polyamine control on their function possesses evolutionary significance. We suggest that acute PSR, caused by trauma for instance, leads to a transient reduction in the density of $\mathrm{nAChRs}$, which protects the brain against excitotoxic damage. In contrast, AD-associated chronic PSR is followed by a persistent and substantial loss of nAChRs, which is partially responsible for the development of cognitive decline (103). Considering pathogenic significance of $\alpha 7 A C h R$ in $A D$, the described polyamine aptitude to control the receptor assembly may explain some features of this devastating disease and be tailored for its treatment.

\section{Polyamines' role in the brain development and neurogenesis}

Polyamines play an essential role in the brain maturation. They participate in the regulation of neurogenesis-related cells division. Pioneering animal studies revealed significantly elevated brain ODC activity and high levels of polyamines during development. Anderson \& Schanberg (1972) demonstrated the postnatal burst in ODC activity in the rat brain, which appeared to be unique for nervous tissue since this phenomenon has not been observed in other tissues such as the heart, skeletal muscles, and liver (104). Later investigations evidenced characteristic activity and expression patterns for the key enzymes responsible for polyamines metabolism and the brain 
polyamines levels themselves, which are high at early developmental stage and radically decrease during neonatal period. An original study by Shaskan et al. (1973) on the brain polyamine content in rats demonstrated a sharp decline in spermine and spermidine levels during the postnatal period (105).

Jasper et al. (1982) revealed that polyamine levels are increased during active neurogenesis in all brain regions but decline subsequently during development (106). Cayre et al. (1997) elegantly demonstrated that putrescine potentiates neurogenesis in the mushroom bodies of adult insects, which are functional analogous of the vertebrate hippocampi (107). The authors conclude that putrescine mimics the effects of a morphogenetic hormone upon adult neuroblast proliferation and transduces the juvenile hormone message in neural tissue. Later on, the same group demonstrated a robust mitogenic effect of putrescine upon mushroom body's neuronal precursors in insects (108). Additionally, spermidine and spermine have been shown to modulate neuronal differentiation, inducing neurite outgrowth.

Kilpeläinen et al. (2000) studied the spatial distribution of ODC in the rodent brain to evidence its high levels in the olfactory bulbs and the hippocampi, which are neurogenesis-active brain regions (109). Malaterre et al. (2004) addressed the question of the polyamines' role in adult mammals neurogenesis and demonstrated a stimulatory effect of putrescine on neural progenitor proliferation (110). Moreover, depletion of putrescine by inhibition of ODC led to a decline in neural progenitor cell proliferation in the dentate gyrus and the subventricular zone.

\section{Polyamines' function in adult organisms}

In order to investigate the precise function of polyamines, numerous models have been utilized. Halmekyto et al. (1991) generated transgenic mice carrying intact human ODC gene and demonstrated expression of human-specific ODC mRNA across tissues (111). In contrast to their wild-type littermates, the transgenic mice exhibited a significantly elevated enzyme activity. Of note, ODC activity was moderately elevated in parenchymal organs such as the liver, kidney, and spleen of the transgenic animals. However, the most remarkable difference has been found in the brain tissue, where the ODC activity was about 70 times higher. 
It is worth mentioning that the extremely elevated ODC activity was not followed by changes in the polyamines' content. The only change in most tissues was an increase in the spermidine to spermine ratio. However, testis and brain demonstrated a different pattern with a dramatic upsurge in putrescine levels. Of note, the elevated brain ODC activity and accumulation of putrescine in the transgenic animals did not result in morphological changes (111).

To clarify whether the high putrescine content influences the functional properties of the brain tissue, Halonene et al. (1993) took advantage of the same model overexpressing the human ODC gene and performed behavioral tests (96). The authors evaluated the rate of memory acquisition in a maze and showed that transgenic mice had significantly impaired performances. Additionally, they proved the aberrant expression of the transgene was most prominent in the brain and led to dramatic increase in putrescine levels. Moreover, the seizure threshold to chemical and electrical stimuli was significantly elevated, even though the concentrations of glutamate and GABA were not changed. Subsequently, the authors suggest that the observed increase in ODC activity following by escalation in brain putrescine levels is neuroprotective rather than detrimental (96).

Polyamines' supplement has been shown to be beneficial for mental health and improve memory acquisition and recall in humans and rodent models (112). However, putrescine application leads to neurotoxicity in some circumstances in rodents. Several lines of evidence prove that the systemic administration of putrescine in supraphysiological doses induces a characteristic toxic response. De Vera et al. (1992) injected rats with putrescine $200 \mathrm{mg} / \mathrm{kg}$, which consequently displayed a behavioral pattern that included wet dog shakes and motor discoordination (113). Of note, the brain concentration of putrescine correlated with the severity of clinical signs. Moreover, histological examination proved the presence of perivascular edema and spongiosis, which were present two hours after the treatment. The authors indicated that the putrescine effects are similar to those of kainic acid at convulsant doses.

Several studies utilized models with local brain administration of polyamines. De Sarro et al. (1993) injected putrescine directly into the rats' pre-piriform cortex (114). The procedure elicited bilateral clonic seizures. Remarkably, injection at the same site of the 
selective NMDA receptor antagonist prior to putrescine, prevented the seizures' development. Moreover, injection of dizocilpine, a specific inhibitor of the polyamine site at the NMDA receptor, before putrescine, significantly protected against seizures elicited by this polyamine.

Sparapani et al. (1997) utilized an in vitro neuronal system, consisting of primary rat cerebellar granule cells, to study the neurotoxicity of spermine, spermidine, and putrescine (115). The mature cultures exposed to increased concentrations of spermine showed dose-dependent cells' death, with the half-maximal effect below $50 \mu \mathrm{M}$. Spermidine demonstrated toxicity, which was about $50 \%$ that of spermine; and putrescine showed a moderate toxicity. Of note, spermine-caused neuronal death was apoptotic by nature and has been prevented by application of the NMDA receptor antagonists. The authors speculate that polyamines are toxic to granule cells and their toxicity is mediated by the NMDA receptors.

De Vera et al. (2008) investigated the effects of spermine and putrescine in human primary cerebral cortical cultures containing both neurons and glia (116). Both spermine and glutamate were toxic to aged neurons (cultures of $26^{\text {th }}$ and later division), though putrescine induced relatively minor effects. Remarkably, co-application of glutamate was found to amplify the effect of spermine; however, spermine showed even higher than glutamate toxicity. Of note, spermine toxicity was inhibited by both Dizocilpine and Ifenprodil, which points to an NMDA receptor depending mechanism.

Several groups demonstrated that numerous pathological factors, including neurotoxic and mechanical lesions, are capable of inducing ODC activity following by a rapid but transient elevation in the brain putrescine levels (117-121). It seems that various stimuli elicit a typical PSR in the brain and the magnitude of the response is stimuli-dependent.

\section{Crosstalk between S6K1 and Arg2}

The mechanistic target of rapamycin (mTOR) is a kinase encoded by the MTOR gene (122). mTOR serves as a central component of two distinct protein complexes, mTOR complex 1 and mTOR complex2, which regulate essential cellular processes, and function as serine/threonine kinases to control cell growth, proliferation, motility, and survival 
(123). mTOR signaling has been shown to be overactive in AD brains and contribute to disease progression (124).

The ribosomal protein S6 kinase beta-1 (S6K1) is a downstream target of mTOR. Mounting evidence indicates an interesting phenomenon related to interaction between S6K1 and Arg2 (125). This interaction may be involved in degeneration and aging. Of note, S6K1 levels and activity are resolutely increased in various human aging tissues, which may play a causal role in age-associated NOS-uncoupling, oxidative stress, and senescence. Remarkably, S6K1 overexpression upregulates Arg2 expression and contrariwise, S6K1 silencing in senescent cells reduces Arg2 expression (125). Moreover, inhibition of S6K1 in the senescent cells decreases Arg2 expression and activity, pointing to a regulatory role of S6K1 activity in Arg2 function and vice versa; Arg2 gene silencing in senescent endothelial cells has been shown to reduce S6K1 activity. On the other hand, Arg2 knockout eliminates S6K1 overactivity (125). Remarkably, Arg2 deficiency extends lifespan in mice (126). This phenomenon is in the line with studies evidencing an antiaging effect of mTOR inhibitors, particularly rapamycin (127).

Several reports link mTOR signaling alterations to age-associated cognitive decline and $A D$ pathogenesis pointing to this kinase as the crossroad between cognitive aging and $A D$ (128)(129). Remarkably, inhibition of mTOR with rapamycin abolishes cognitive deficits and diminishes $A \beta$ levels in a mouse model of $A D$ (130). Moreover, reducing S6K1 expression in a different rodent $A D$ model improves spatial memory and synaptic plasticity (131).

Of note, mTOR complex 1 negatively regulates autophagy, which is the indispensable cellular mechanism to eliminate unnecessary and dysfunctional components (132). The housekeeping role of autophagy in the brain is particularly evident in neurons loaded with pathogenic misfolded proteins, such as $A \beta$ aggregates (133). In $A D$ the autophagiclysosomal dysfunction causes severe neurodegenerative phenotypes associated with accumulations of lysosomes and autophagic vacuoles (Fig. 4) (134,135).

Additional evidence indicates that impaired autophagy and enhanced Arg2-mTOR crosstalk are strongly implicated in vascular aging and atherosclerosis. Xiong et al. (2014) credibly demonstrated that Arg2 impairs endothelial autophagy function independently of 
the arginine ureahydrolase activity but via activation of S6K1 (136). Accordingly, it was hypothesized that disruption of the S6K1-Arg2 crosstalk by inhibition of Arg2 or S6K1 may restore NOS function, improve NO production, reduce inflammation, and eventually, preclude senescence and decelerate aging (137).

More recent investigations have deciphered the precise mechanisms of the mTOR complex1 pathway Arg2-associated activation contributing to cell senescence and apoptosis. It was shown that overexpression of Arg2 induces the re-distribution of lysosome and mTOR from perinuclear area to cell periphery and activation of mTORS6K1 pathway (Fig. 4) (138). Therefore, S6K1-Arg2 crosstalk represents a promising therapeutic target to slowdown the age-associated processes and treat the neurodegenerative diseases.

\section{Polyamine pathway in Alzheimer's disease}

Despite a century-long investigation, no clear understanding of $A D$ etiology and pathogenesis is achieved. Several definite hallmarks of the disease have been described and studied with precision, however, the causal relationships between them and clinical dementia remain to be revealed. Mounting evidence indicates that $A D$ is a pervasive metabolic disorder characterized and possibly caused by dysregulation of numerous biochemical pathways, which underlie its complex pathogenesis (139).

Many groups have tried to correlate the AD-associated brain metabolic changes with clinical manifestation and objective morphological alterations. In their pioneering work, Bernstein \& Müller (1995) convincingly demonstrated augmented immunopositivity for ODC in neocortical neurons of AD patients (140). Accordingly, the authors hypothesized that the polyamine system is actively involved in neurorestorative processes taking place in AD brains trying to cope with emerging neurodegeneration. Additionally, they proposed that ODC is activated to modulate the NMDA receptor function. Morrison \& Kish proved that brain polyamine levels are substantially altered in AD brains (141). The authors suggested that abnormal polyamine metabolism is involved in the AD-associated neurodegeneration due to its influence upon calcium dynamics and glutamate receptors function. The scientists substantiated the early rodent-based data by human postmortem research and demonstrated significantly elevated brain levels of ODC in the perinatal 
period, which indicated a developmental role of polyamines (142). Moreover, the authors linked the increased levels of ODC in the temporal cortex of AD patients' brains with the disease progression.

Yatin et al. (1999) confirmed in an elegant in vitro study that $A \beta$-treated hippocampal neurons show an increased polyamine metabolism in response to free radical-mediated oxidative stress (143). Additionally, the authors showed that the free radical scavenger, vitamin E, application prevents these attenuations. Thus, the authors speculated that the observed polyamine response is a reaction to $A \beta$-mediated oxidative stress. However, in a modified study, the same group demonstrated a strong synergistic neurotoxic effect of $A \beta$ applied together with spermine to treat cultured neurons (144). The authors suggest that $A \beta$-related spermine accumulation is harmful to neurons and hypothesize that in the AD brains polyamine pathway' regulatory enzymes are damaged by oxidative insults and incapable of polyamine synthesis and uptake's regulation, which leads to accumulation of intracellular polyamines up to toxic levels. This hypothesis accords with the data acquired in the pioneering in vivo experiments utilizing an ODC inhibitor, DFMO, in the brain ischemia/reperfusion paradigm in rodents (145). It has been well-established that administration of DFMO results in a dose-dependent beneficial effect upon hippocampal neurons survival rate indicating that ODC activity and the polyamines' levels play a significant role in the brain response to ischemic injury. Of note, extensive ROS generation follows cerebral ischemia/reperfusion (146).

The same ODC inhibitor has been used by Kan et al. (2015) to show protective effect of the treatment on cognitive functions in AD mice (8). The authors disclosed a substantial cerebral arginine deprivation and immune suppression caused by arginase overexpression in the $A D$ mice brains. Despite a very promising phenotype observed in $A D$ model, subsequent 12-month-long clinical trial did not demonstrate a noticeable effect in an AD patient (147).

Rodent studies prove a substantial polyamine dysregulation in a model of tauopathy (148). Accordingly, it has been proposed that pathological tau represents a chronic physiological stressor provoking a typical PSR. The authors took advantage of transgenic mice harboring human tau P301L associated with frontotemporal dementia mutation to 
show the brain accumulation of putrescine and acetylated spermidine. Additionally, they demonstrated that acetylspermidine accretion intensifies tau oligomerization, however, SSAT repression reduces tau aggregation. These data signify a detrimental role of polyamine acetylated products accumulation on tau fate in the brain (148).

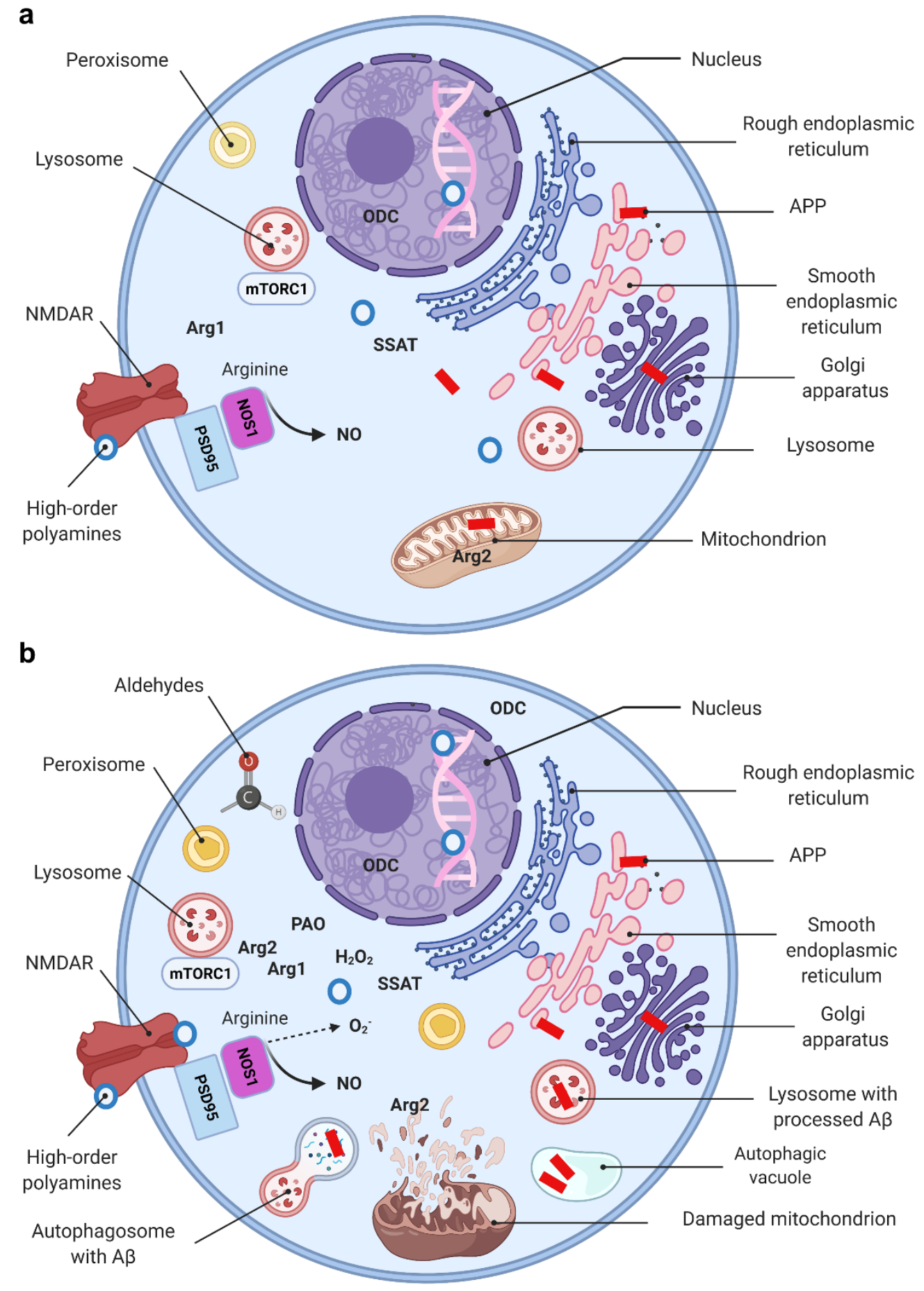


Fig. 4 Molecular basis of AD (a simplified model). Schematic representation of a "normal" (a) and a dysfunctional (b) neuron with main organelles involved in APP processing and PSR. Following synthesis, APP undergoes posttranslational modifications in the ER and Golgi where it generates $A \beta$. In the healthy brain $A \beta$ is localized in perikarya, trans-Golgi network, Golgi-derived vesicles (a), while oxidative stress upsurges intralysosomal $A \beta$ content (b) (149). Mitochondria are essential for maintaining neuronal integrity and function. Arg2 is a typical mitochondriaassociated enzyme (a). Mitochondria are targets for A /ROS-mediated damage, which leads to swelling, outer membrane rupture, and followed by Arg2 appearance in the cytoplasm. Arg2, in turn, induces re-distribution of lysosome and mTOR from perinuclear area to cell periphery (b), activates mTORC1-S6K1 signaling and contributes to cell senescence phenotype characterized by impaired autophagy and apoptosis. This process eventuates in impediment of the autophagolysosomes maturation and lysosome-associated $A \beta$ degradation, and leads to $A \beta$ accumulation in autophagic vacuoles (b). Peroxisomes are not competent to cope with growing oxidative stress and become target for ROS. Oxidative stress leads to Arg1 overexpression, ODC translocation to the cytoplasm, and eventuates by polyamine overproduction (PSR). High-order polyamines stabilize the DNA conformation and modulate the chromatin structure and gene transcription via ionic interactions (a). Their elevated levels shut down some vital genes (b). Extensive polyamine catabolism is followed by the generation of hydrogen peroxide and cytotoxic aldehydes. NOS1 deprived of arginine undergoes uncoupling and switches to the production of superoxide anion. NMDA receptor function is modulated by polyamines via a special recognition site.

Of importance, several sets of data pointed to arginase, which is up-stream to ODC enzyme, as the main cause of the AD-related polyamine pathway abnormalities. Hansmannel et al. revealed a significant escalation of Arg2 levels in AD brains compared to healthy controls (150). Moreover, the authors associated the presence of the rare Arg2 allele with increased risk of $A D$ onset and posed a question on the urea cycle involvement in $A D$ pathogenesis. Additionally, in the mentioned above murine study (8) the researchers revealed a significant elevation in the brain Arg1 levels correlating with the onset of cognitive decline. We published data showing a significant increase in the intracellular Arg1 levels in the hippocampal neurons of AD mice compared to wild-type animals (11). A pioneering metabolomic human study revealed dramatically elevated (by several folds) levels of urea, a by-product of arginase (Fig. 2), in all AD patients' brain 
regions compared to healthy controls indicating disease-associated overactivation of arginase (151).

Other groups utilized advanced techniques to prove the AD-associated polyamine metabolism disturbances. Inoue et al. (2013) applied ultra-performance liquid chromatography coupled with mass spectrometry to profile and differentiate metabolically the frontal, parietal, and occipital lobes of the AD patients' brains in comparison with healthy controls (9). The authors disclosed a significant increase in spermidine, spermine, and putrescine levels, without a change in ornithine levels in frontal and parietal lobes of AD patients' brains.

Liu et al. (2014) compared the metabolic profile of arginine and its downstream metabolites in brains from AD patients with healthy brains to reveal significant differences (152). The authors also analyzed the activity and protein levels of NOS and arginase and demonstrated their inverse age- and region-specific alterations linked to significant elevation in the rate of arginase activity.

Recently, Mahajan et al. (2020) applied a targeted metabolomic and transcriptomic study to demonstrate dysregulation of multiple metabolic networks related to brain transmethylation and polyamine pathway in AD (153). The authors reported significant, correlating with severity of disease, alterations in concentrations of numerous metabolites in AD brains compared to control samples. These metabolites represent biochemical reactions in the polyamine pathway (with significantly higher spermidine concentrations in AD brains) and urea cycle. A transcriptomics analysis accords with the metabolomics results, further revealing significant alterations in gene expression of pivotal polyamine metabolism regulators. Of note, SSAT and PAO demonstrated significantly elevated levels of expression in entorhinal cortex and hippocampus of AD patients' brains.

Remarkably, the levels of ornithine are generally normal in AD brains despite a significant elevation in the urea levels, which is a product of the same reaction (Fig. 2), even though the levels of arginine and its brain bioavailability are decreased (56). This paradox misled some researchers to speculate that the defective urea clearance characterizes $A D$ (151). Though, apparently, ornithine generated by up-regulated arginase in AD brains is immediately consumed by OTC and ODC, which are overactivated as well (54). 
It is noteworthy that metabolomics investigations of AD patients' CSF detect a relative disease-associated reduction in arginine levels $(154,155)$. Moreover, the patients with mild cognitive impairment $(\mathrm{MCl})$ are characterized by substantially lower than in controls urine arginine levels (156). These patients also demonstrate a reduced global arginine bioavailability ratio positively correlating with the Mini-Mental Status Examination score, which points to diminished urinary arginine levels as an early diagnostic biomarker of $\mathrm{MCl}$ and $A D$.

Additionally, metabolomics studies of human plasma clearly indicate differentially affected polyamine and arginine metabolism in $A D$ patients. As a result, the subjects with $\mathrm{MCl}$ are easily distinguishable from healthy controls and AD patients (157), which gives hope for $A D$ diagnosis at early stages with routine laboratory blood tests and further supports our perspective on $A D$ as a brain expression of a complex metabolic disorder (139).

It should be pointed out that arginase upregulation in the AD brain causes NOS and ADC substrate deficiency. In this case, NOS generates diminished amounts of NO and switches into production of superoxide anion, which aggravates the oxidative stress (Fig. 4b). Additionally, ADC lacking the regular substrate, arginine, consumes ornithine to produce putrescine, which further upsurges the polyamines' levels (Fig. 2). Moreover, spermine directly inhibits NOS activity in various cell types. In the rodent brain this effect upon NOS1 activity is very prominent (158) and leads to improvement in arginine bioavailability for arginase in the AD brain, facilitates the polyamine synthesis, and closes the vicious circle of neurodegeneration.

On the other hand, overactivated PAO generates hydrogen peroxide to exacerbate the oxidative damage (Fig. 4b). Likewise, a relative decline in the levels of agmatine deprives the brain of the potent neuronal protector (159).

In our studies, we utilized a non-competitive arginase inhibitor, norvaline, which also inhibits S6K1 (160), to moderate the activity of the brain arginase in AD mice (11). The spatial memory was significantly improved in the treated animals, and the improvement was associated with a reduction in neuroinflammation. Additionally, we evidenced a treatment-related decline in $\beta$-amyloidosis (161), followed by an improvement in the BBB integrity (162) and neurogenesis (163). Of note, the hippocampal levels of Arg1 protein 
significantly reduced following the treatment. Yang et al. (2014) credibly demonstrated that Arg1 expression is regulated by histone deacetylase 4 (HDAC4)-mediated histone acetylation (164). Our data proved that HDAC4 levels decrease dramatically following the treatment with norvaline. Moreover, its functionally active form, demonstrated a substantial reduction in levels (163). Of importance, HDAC inhibitors are promising ADmodifying agents (165), therefore, we speculate that HDAC is partially responsible for the phenotype we observed.

Our approach has been recently tested with another non-competitive arginase inhibitor, citrulline, in AD mice (166). The treated animals demonstrated increased arginine CSF levels and performed significantly better in a maze. The authors demonstrated that the therapeutic time window is limited to the period prior to the development of cognitive symptoms, like in our studies. Consequently, we suggest that arginase gradually alters its functional role during the disease development and propose that treatment strategy directed at fine-tuning of arginase activity with natural inhibitors is a promising ADmodifying approach capable of interfering with various aspects of this pathology. Moreover, we state that polyamine metabolism dysregulation is a causal factor of neurodegeneration, but not just a signature. Still, regardless of several successful attempts to interfere with PSR activity at various levels (Table 1) and halt the development of AD-like pathology in animal models, the chicken or the egg causality dilemma remains to be resolved.

In this context, it is worth noting that several groups tried to manipulate Arg1 expression in the models of familial frontotemporal dementia (167) and AD (168). Remarkably, Arg1 overexpression mitigated hippocampal atrophy in transgenic mice, but Arg1 deletion in myeloid cells increased tau accumulation relative to Arg1-sufficient mice (167). Of note, rTg4510 mice used in this study express a human tau containing the mutation linked to familial frontotemporal dementia. The animals progressively develop age-related neurofibrillary tangles, neuronal loss, and behavioral impairments (169). The tangles are observed by about 4 months of age and the deficits in spatial navigation are seen as early as 1.3 months of age (169). In the cited above study (167), four-month-old rTg4510 mice were injected in the hippocampus with an rAAV9-Arg1 construct. The animals 
demonstrated elevated levels of Arg1 throughout the hippocampus that was associated with reduced tangle pathology; however, no behavioral effect has been reported. Another very recent study utilized haploinsufficiency of Arg1 in myeloid cells of Tg2576 mice (168). This manipulation promoted $A \beta$ deposition and exacerbated behavioral impairment.

\begin{tabular}{|c|c|c|c|c|}
\hline $\begin{array}{c}\text { Target } \\
\text { gene }\end{array}$ & Manipulation/ agent & Mechanism & Effect & References \\
\hline ODC & DFMO & $\begin{array}{c}\text { Irreversible ODC } \\
\text { inhibition }\end{array}$ & Neuroprotective & (8) \\
\hline SSAT & KO mouse & Deletion of SSAT & Neuroprotective & (148) \\
\hline PAO & MDL 72527 & $\begin{array}{c}\text { Irreversible PAO } \\
\text { inhibition }\end{array}$ & Neuroprotective & $(170)(171)$ \\
\hline $\mathrm{SMO}$ & Transgenic mouse & SMO overexpression & Neurotoxic & $(172)$ \\
\hline Arg1, Arg2 & Norvaline & $\begin{array}{c}\text { Noncompetitive } \\
\text { arginase inhibition }\end{array}$ & Neuroprotective & $\begin{array}{l}(11)(161) \\
(162)(163)\end{array}$ \\
\hline Arg1, Arg2 & Resveratrol & $\begin{array}{c}\text { Noncompetitive } \\
\text { arginase inhibition }\end{array}$ & Neuroprotective & (173) \\
\hline Arg1, Arg2 & Chloroquine & $\begin{array}{c}\text { Competitive arginase } \\
\text { inhibition }\end{array}$ & Neuroprotective & (174) \\
\hline Arg1, Arg2 & Citrulline & $\begin{array}{c}\text { Noncompetitive } \\
\text { arginase inhibition }\end{array}$ & Neuroprotective & $(166)(175)$ \\
\hline Arg2 & KO mouse & Deletion of Arg2 & Neuroprotective & $(176)$ \\
\hline Arg1 & $\begin{array}{l}\text { AAV-mediated } \\
\text { overexpression }\end{array}$ & $\begin{array}{l}\text { Arg1 overexpression } \\
\text { in the hippocampus }\end{array}$ & Neuroprotective & (167) \\
\hline $\begin{array}{l}\text { Arg1 in } \\
\text { myeloid } \\
\text { cells }\end{array}$ & Transgenic mouse & $\begin{array}{c}\text { Arg1 } \\
\text { haploinsufficiency }\end{array}$ & Neurotoxic & $(168)$ \\
\hline
\end{tabular}

Table 1. Possible theranostic applications and their effects within the polyamine metabolism.

There are several possible explanations for these contradictory results. First of all, overexpression methodology obviously does not represent physiologic phenomena (177). It creates supraphysiological levels of protein that dysregulate many biological pathways, interfere with the protein assembly, which severely confuses the results' interpretation 
(178). Knockout technique is problematic and sometime inappropriate as well (179), because, apparently, the absence of one gene alters expression of other genes and changes entire developmental programs (180). Nevertheless, the question of how Arg1 and Arg2 differ in their biological function is still open.

Furthermore, in our opinion, it is critical to start the treatment prior to any cognitive impairment symptoms, literally precluding the neurodegeneration. This is the only way to eradicate dementia. There are sensitive periods for the most successful therapeutic intervention. After the vicious cycle is already ongoing and neurodegeneration is pronounced, it is too late to intervene, unfortunately.

\section{Evolutionary perspective on aging and Alzheimer's disease}

Inevitable aging and death are universal phenomena across multicellular organisms, indicating that they are the natural consequences of life and are not related to disease. Moreover, average lifespan is a species-specific characteristic, which varies significantly between different species pointing to natural limits of life expectancy. Nevertheless, in recent decades, human longevity well exceeds the ever-chronicled numbers. Still, this spectacular phenomenon is accompanied by increased somatic and mental morbidity. In this context, $A D$ is a very interesting example of the evolution-related pathology. $A D$ is a peculiar and specific to Homo sapiens' pathology that may relate to adaptive changes transpired only in evolutionary recent history. Apparently, many of the AD-associated riskfactors were not present prior to industrialization era, potentially reducing the prevalence of the disease in ancient times. However, the recent theories of aging predicated upon evolutionary concepts provide an alternative explanation for the recently increased $A D$ morbidity (181).

In accordance with a prevailing view, the senile dementia of the Alzheimer type is a logical consequence of continuously increasing lifespan and an inevitable manifestation of senescence. Some estimations even predict dementia by the age of 130 for everyone as an unescapable toll of longevity (182). Another hypothesis of "antagonistic pleiotropy" has been articulated by several groups who comprehend some genes' expression to be extremely beneficial or even necessary during an early phase of the life cycle but detrimental at the late phase (183). 
This approach refers to the incredible plasticity of the human brain, which is critical for learning and memory during development, as a particularly beneficial capability associated with an increased expression of neuroplasticity-related genes. On the other hand, this theory considers these genes' expression as a detrimental and bioenergetically costly event for the aging brain, which plays a critical role in the AD pathogenesis (184). Accordingly, it was hypothesized that susceptibility genes associated with $A D$ development possess pleiotropic effects (185). The ubiquitous in ancestral species APOE\&4 precursor gene has become the strongest AD genetic risk-factor (186). However, this $\varepsilon 4$ allele is apparently beneficial for young individuals' mental and physical health and confers a risk for atherosclerosis and cognitive decline only in advanced ages. Hence, it was proposed that APOE gene represents an example of antagonistic pleiotropy (187). Antagonistic pleiotropy has also been suggested for tau-protein role in the AD development (188).

Mounting evidence indicates general down-regulation of polyamine biosynthesis during aging (189). Pioneering work by Duffy \& Kremzner (1977) in human fibroblasts demonstrated that cell senescence is associated with the reduction in ODC activity (190). Beyer et al. (1992) established that aging alters ODC activity and leads to decrease in polyamine content (191). Lin et al. (2018) reported a significant 2.65-fold down-regulation of ODC levels and 4.73-fold of PAO levels in 24-month-old mice muscle tissue compared to 3-month-old mice (192). Accordingly, spermidine intracellular concentrations tend to decline during normal aging as well; though, its administration evidently extends the lifespan in various model organisms, including yeast, worms, flies, and mice (193). Contrariwise, depletion of endogenous polyamines causes hyperacetylation, ROS generation, and early necrotic death eventuating in diminished lifespan (193).

Surprisingly, Arg1 levels gradually increase in skeletal muscles of mice during aging (194), nevertheless, its upturn is not followed by elevation in polyamine levels. This phenomenon may reflect a compensatory mechanism, which in any case is inadequate to support the polyamine content in aged organism, and causes arginine deficiency, NOS and ADC substrate deprivation. Of importance, the age-associated upregulation of 
arginase has been suggested to be involved in various pathologies. Endothelial dysfunction (195), hypertension (196), and diabetes mellitus (197) are among them.

In this context, we comprehend aging as an extremely intricate genetically programmed and epigenetically influenced natural biological process, which may be accelerated by stressful or harmful stimuli leading to cell senescence and eventually death.

\section{Conclusions}

For decades the confirmed diagnosis of $A D$ had been dependent upon the postmortem brain investigation and analysis of the $\beta$-amyloid deposition patterns and identification of the neurofibrillary tangles. Nevertheless, the canonical pathological changes poorly correlate with clinical manifestation, laboratory findings, and even the prognosis of the disease. Moreover, a cornucopia of clinical trials aimed at lessening of amyloid and/or tau brain burden, yielded no reliable disease-modifying therapy. Thus, it seems that the presence of amyloid plaques and neurofibrillary tangles in the brain does not presume the causal relationships between the hallmarks and other AD-associated neurodegenerative processes and cannot be recognized as etiological factors.

A novel perspective on $\mathrm{AD}$, with emphasis upon its evolutionary and metabolic aspects, proposes an inclusive reassessment of the causal relationships between traditional hallmarks, homeostatic features, and clinical manifestations. Accordingly, we comprehend $A D$ as a chronic disease characterized by an unwinding vicious cycle of metabolic aberrations with a series of pathogenetic steps that reinforce each other, lead to neurodegeneration, and eventuate in clinical dementia. We envision the AD-associated polyamine response as an integrated part of the conserved adaptive mechanism and emphasize that prolonged induction of polyamines possesses limited efficacy in coping with gradual oxidative stress and may not have beneficial effects due to toxicity issues. We also underline that continual induction of the polyamine pathway is followed by arginine brain deprivation, extensive catabolic oxidation of polyamines, ROS generation, and induction of oxidative stress, which aggravate the AD symptoms.

Accruing evidence highlights polyamines as the pivotal players in signaling responses to various environmental stimuli, which are involved in various aspects of metabolism, 
maintenance of antioxidant capacity, and osmotic regulation. This pathway represents a metabolic hub existing virtually in all phyla, including simple organisms, plants, and mammals, and constitutes an evolutionary-conserved adaptive response. Still, many questions remain open.

We indicate the beneficial role of the polyamines' levels elevation following a short-term stimulus while under chronic stress, in some conditions, and in aging organism principally, may lead to an aberrant polyamine metabolism and, eventually, become maladaptive. Enduring stimuli such as repetitive brain trauma, cerebral arteriosclerosis-associated ischemia, metabolic stress, etc. lead to a deviant PSR and initiate the vicious cycle of neurodegeneration with distinctive $\beta$-amyloid aggregation and tau protein hyperphosphorylation, the main hallmarks of $A D$, which are just epiphenomena of the upstream pathology.

Additionally, we suggest that $A D$ may be driven by various pleiotropic mechanisms, which deserve close attention and further research. This view approaches the enigmatic $A D$ pathogenesis within the framework of evolutionary sciences that comprehend some genes as necessary for early development, but which are harmful in the elderly. Consequently, we believe that investigation of the fragile equilibrium between neurodegenerative and neuroprotective effects of ROS, NO, arginase, $\beta$-amyloid, $A P O E \varepsilon 4$, and intimately pertinent to them, neuroinflammation in the aging brain, may eventually decipher the $A D$ pathogenesis conundrum and lead to efficient diseasemodifying treatment.

\section{Abbreviations}

ROS reactive oxygen species

PSR polyamine stress response

AD Alzheimer's disease

LUCA last universal common ancestor

UPR unfolded protein response

ER endoplasmic reticulum

ODC ornithine decarboxylase 
ADC arginine decarboxylase

AGM agmatinase

CNS central nervous system

$\mathrm{H}_{2} \mathrm{O}_{2}$ hydrogen peroxide

Arg arginase

OTC ornithine transcarbamylase

CPS1 carbamoyl phosphate synthetase 1

LPS lipopolysaccharide

TNFa tumor necrosis factor alpha

LDL low-density lipoprotein

MMP mitochondrial membrane potential

ODC-AZ ODC antizyme

SSAT spermidine/spermine acetyltransferase

PAO polyamine oxidase

SMO spermine oxidase

DNA deoxyribonucleic acid

RNA ribonucleic acid

AMPA a-amino-3-hydroxy-5-methyl-4-isoxazolepropionic acid

nAChR nicotinic acetylcholine receptors

NMDA N-methyl-D-aspartate

DFMO difluoromethylornithine

mTOR mechanistic target of rapamycin

S6K1 ribosomal protein S6 kinase beta-1

HDAC histone deacetylase

KO knockout 


\section{References}

1. Rhee HJ, Kim EJ, Lee JK. Physiological polyamines: simple primordial stress molecules. J Cell Mol Med. 2007;11(4):685-703. doi:10.1111/j.15824934.2007.00077.x

2. Morris DR. A new perspective on ornithine decarboxylase regulation: prevention of polyamine toxicity is the overriding theme. J Cell Biochem. 1991 Jun;46(2):1025. doi: $10.1002 / j c b .240460203$.

3. Michael AJ. Polyamine function in archaea and bacteria. J Biol Chem. 2018 Nov 30;293(48):18693-18701. doi: 10.1074/jbc.TM118.005670.

4. Michael AJ. Polyamines in Eukaryotes, Bacteria, and Archaea. J Biol Chem. 2016 Jul 15;291(29):14896-903. doi: 10.1074/jbc.R116.734780.

5. Sequera-Mutiozabal M, Antoniou C, Tiburcio AF, Alcázar R, Fotopoulos V. Polyamines: Emerging Hubs Promoting Drought and Salt Stress Tolerance in Plants. Curr Mol Biol Reports. 2017; 28-36. https://doi.org/10.1007/s40610-0170052-z

6. Miller-Fleming L, Olin-Sandoval V, Campbell K, Ralser M. Remaining Mysteries of Molecular Biology: The Role of Polyamines in the Cell. J Mol Biol. 2015 Oct 23;427(21):3389-406. doi: 10.1016/j.jmb.2015.06.020.

7. Gilad GM, Gilad VH. Polyamines in neurotrauma. Ubiquitous molecules in search of a function. Biochem Pharmacol. 1992 Aug 4;44(3):401-7. doi: 10.1016/00062952(92)90428-I.

8. Kan MJ, Lee JE, Wilson JG, Everhart AL, Brown CM, Hoofnagle AN, Jansen M, Vitek MP, Gunn MD, Colton CA. Arginine deprivation and immune suppression in a mouse model of Alzheimer's disease. J Neurosci. 2015 Apr 15;35(15):5969-82. doi: 10.1523/JNEUROSCI.4668-14.2015.

9. Inoue $\mathrm{K}$, Tsutsui $\mathrm{H}$, Akatsu $\mathrm{H}$, Hashizume $\mathrm{Y}$, Matsukawa $\mathrm{N}$, Yamamoto $\mathrm{T}$, Toyo'oka T. Metabolic profiling of Alzheimer's disease brains. Sci Rep. 2013;3:2364. doi: 10.1038/srep02364. 
10. Handley RR, Reid SJ, Brauning R, Maclean P, Mears ER, Fourie I, et al. Brain urea increase is an early Huntington's disease pathogenic event observed in a prodromal transgenic sheep model and HD cases. Proc Natl Acad Sci. 2017; Dec 26;114(52):E11293-E11302. doi: 10.1073/pnas.1711243115.

11. Polis B, Srikanth KD, Elliott E, Gil-Henn H, Samson AO. L-Norvaline Reverses Cognitive Decline and Synaptic Loss in a Murine Model of Alzheimer's Disease. Neurotherapeutics. 2018 Oct;15(4):1036-1054. doi: 10.1007/s13311-018-0669-5.

12. Handa AK, Fatima T, Mattoo AK. Polyamines: Bio-Molecules with Diverse Functions in Plant and Human Health and Disease. Front Chem. 2018;6:10. doi:10.3389/fchem.2018.00010

13. Abbadie C, Pluquet O, Pourtier A. Epithelial cell senescence: an adaptive response to pre-carcinogenic stresses? Cell Mol Life Sci. 2017 Dec;74(24):44714509. doi: 10.1007/s00018-017-2587-9.

14. Abbadie C, Pluquet O. Unfolded Protein Response (UPR) Controls Major Senescence Hallmarks. Trends Biochem Sci. 2020 May;45(5):371-374. doi: 10.1016/j.tibs.2020.02.005.

15. Swenson BL, Meyer CF, Bussian TJ, Baker DJ. Senescence in aging and disorders of the central nervous system. Translational Medicine of Aging. 2019 Jan 1;3:17-25. https://doi.org/10.1016/j.tma.2019.01.002

16. Martínez-Cué C, Rueda N. Cellular Senescence in Neurodegenerative Diseases. Front Cell Neurosci. 2020;14:16. doi:10.3389/fncel.2020.00016

17. Gilad GM, Gilad VH. Overview of the brain polyamine-stress-response: regulation, development, and modulation by lithium and role in cell survival. Cell Mol Neurobiol. 2003 Oct;23(4-5):637-49. doi: 10.1023/a:1025036532672.

18. Wallace HM, Fraser AV, Hughes A. A perspective of polyamine metabolism. Biochem J. 2003;376(Pt 1):1-14. doi:10.1042/BJ20031327

19. Shimizu H, Daly JW, Creveling CR. A radioisotopic method for measuring the formation of adenosine 3 ', 5 '-cyclic monophosphate in incubated slices of brain. $J$ 
Neurochem. 1969 Dec;16(12):1609-19. doi: 10.1111/j.1471-4159.1969.tb10360.x.

20. Schmidt-Glenewinkel T, Nomura Y, Giacobini E. The conversion of lysine into piperidine, cadaverine, and pipecolic acid in the brain and other organs of the mouse. Neurochem Res. 1977 Dec;2(6):619-37. doi: 10.1007/BF00963776.

21. Stepita-Klauco M, Dolezalova H. Cadaverine in the brain of axenic mice. Nature. 1974 Nov 8;252(5479):158-9. doi: 10.1038/252158a0.

22. Igarashi K, Kashiwagi K, Hamasaki H, Miura A, Kakegawa T, Hirose S, Matsuzaki $\mathrm{S}$. Formation of a compensatory polyamine by Escherichia coli polyaminerequiring mutants during growth in the absence of polyamines. J Bacteriol. 1986 Apr;166(1):128-34. doi: 10.1128/jb.166.1.128-134.1986.

23. Burrell M, Hanfrey CC, Murray EJ, Stanley-Wall NR, Michael AJ. Evolution and multiplicity of arginine decarboxylases in polyamine biosynthesis and essential role in Bacillus subtilis biofilm formation. J Biol Chem. 2010 Dec 10;285(50):39224-38. doi: 10.1074/jbc.M110.163154.

24. Li, Gen, et al. "Agmatine: An Endogenous Clonidine-Displacing Substance in the Brain." Science, vol. 263, no. 5149, 1994, pp. 966-969.

25. Iyo AH, Zhu MY, Ordway GA, Regunathan S. Expression of arginine decarboxylase in brain regions and neuronal cells. $J$ Neurochem. 2006;96(4):1042-1050. doi:10.1111/j.1471-4159.2005.03544.x

26. Raasch W, Regunathan S, Li G, Reis DJ. Agmatine, the bacterial amine, is widely distributed in mammalian tissues. Life Sci. 1995;56(26):2319-30. doi: 10.1016/0024-3205(95)00226-v. PMID: 7791519.

27. Regunathan S, Reis DJ. Characterization of arginine decarboxylase in rat brain and liver: distinction from ornithine decarboxylase. J Neurochem. 2000 May;74(5):2201-8. doi: 10.1046/j.1471-4159.2000.0742201.x.

28. Gilad GM, Gilad VH, Rabey JM. Arginine and ornithine decarboxylation in rodent brain: coincidental changes during development and after ischemia. Neurosci Lett. 1996 Sep 20;216(1):33-6. doi: 10.1016/0304-3940(96)12996-7. 
29. Onal A, Soykan N. Agmatine produces antinociception in tonic pain in mice. Pharmacol Biochem Behav. 2001 May-Jun;69(1-2):93-7. doi: 10.1016/s00913057(01)00509-3.

30. Regunathan S, Piletz JE. Regulation of inducible nitric oxide synthase and agmatine synthesis in macrophages and astrocytes. Ann N Y Acad Sci. 2003 Dec;1009:20-9. doi: 10.1196/annals.1304.002.

31. Zhu MY, Piletz JE, Halaris A, Regunathan S. Effect of agmatine against cell death induced by NMDA and glutamate in neurons and PC12 cells. Cell Mol Neurobiol. 2003 Oct;23(4-5):865-72. doi: 10.1023/a:1025069407173.

32. Gilad GM, Gilad VH. Accelerated functional recovery and neuroprotection by agmatine after spinal cord ischemia in rats. Neurosci Lett. 2000 Dec 22;296(23):97-100. doi: 10.1016/s0304-3940(00)01625-6.

33. Peters D, Berger J, Langnaese K, et al. Arginase and Arginine Decarboxylase Where Do the Putative Gate Keepers of Polyamine Synthesis Reside in Rat Brain?. PLoS One. 2013;8(6):e66735. doi:10.1371/journal.pone.0066735

34. Dowling DP, Di Costanzo L, Gennadios HA, Christianson DW. Evolution of the arginase fold and functional diversity. Cell Mol Life Sci. 2008;65(13):2039-2055. doi:10.1007/s00018-008-7554-z

35. Caldwell RB, Toque HA, Narayanan SP, Caldwell RW. Arginase: an old enzyme with new tricks. Trends Pharmacol Sci. 2015 Jun;36(6):395-405. doi: 10.1016/j.tips.2015.03.006.

36. Vockley JG, Jenkinson CP, Shukla H, Kern RM, Grody WW, Cederbaum SD. Cloning and characterization of the human type II arginase gene. Genomics. 1996 Dec 1;38(2):118-23. doi: 10.1006/geno.1996.0606. PMID: 8954792.

37. Reczkowski RS, Ash DE. Rat liver arginase: kinetic mechanism, alternate substrates, and inhibitors. Arch Biochem Biophys. 1994 Jul;312(1):31-7. doi: 10.1006/abbi.1994.1276.

38. Samson ML. Drosophila arginase is produced from a nonvital gene that contains 
the elav locus within its third intron. J Biol Chem. 2000; 275 (40), 31107-14, https://doi.org/10.1074/jbc.M001346200

39. Dzik JM. Evolutionary roots of arginase expression and regulation. Front Immunol. 2014;5:544. doi:10.3389/fimmu.2014.00544

40. Jenkinson CP, Grody WW, Cederbaum SD. Comparative properties of arginases. Comp Biochem Physiol B Biochem Mol Biol. 1996 May;114(1):107-32. doi: 10.1016/0305-0491(95)02138-8. PMID: 8759304.

41. Lange PS, Langley B, Lu P, Ratan RR. Novel roles for arginase in cell survival, regeneration, and translation in the central nervous system. J Nutr. 2004 Oct;134(10 Suppl):2812S-2817S; discussion 2818S-2819S. doi: 10.1093/jn/134.10.2812S.

42. Stewart JA, Caron H. Arginases of mouse brain and liver. J Neurochem. 1977 Oct;29(4):657-63. doi: 10.1111/j.1471-4159.1977.tb07783.x.

43. Peters D, Berger J, Langnaese K, et al. Arginase and Arginine Decarboxylase Where Do the Putative Gate Keepers of Polyamine Synthesis Reside in Rat Brain?. PLoS One. 2013;8(6):e66735. doi:10.1371/journal.pone.0066735

44. Esch F, Lin KI, Hills A, Zaman K, Baraban JM, Chatterjee S, Rubin L, Ash DE, Ratan RR. Purification of a multipotent antideath activity from bovine liver and its identification as arginase: nitric oxide-independent inhibition of neuronal apoptosis. J Neurosci. 1998 Jun 1;18(11):4083-95. doi: 10.1523/JNEUROSCI.1811-04083.1998.

45. Morris SM Jr, Bhamidipati D, Kepka-Lenhart D. Human type II arginase: sequence analysis and tissue-specific expression. Gene. 1997 Jul 9;193(2):15761. doi: 10.1016/s0378-1119(97)00099-1.

46. Jones ME, Anderson AD, Anderson C, Hodes S. Citrulline synthesis in rat tissues. Arch Biochem Biophys. 1961;95(3):499-507. https://doi.org/10.1016/00039861(61)90182-5.

47. Morris SM Jr. Regulation of enzymes of the urea cycle and arginine metabolism. 
Annu Rev Nutr. 2002;22:87-105. doi: 10.1146/annurev.nutr.22.110801.140547.

48. Chandra S, Romero MJ, Shatanawi A, Alkilany AM, Caldwell RB, Caldwell RW. Oxidative species increase arginase activity in endothelial cells through the RhoA/Rho kinase pathway. Br J Pharmacol. 2012 Jan;165(2):506-19. doi: 10.1111/j.1476-5381.2011.01584.x.

49. Ryoo S, Bhunia A, Chang F, Shoukas A, Berkowitz DE, Romer LH. OxLDLdependent activation of arginase II is dependent on the LOX-1 receptor and downstream RhoA signaling. Atherosclerosis. 2011 Feb;214(2):279-87. doi: 10.1016/j.atherosclerosis.2010.10.044.

50. Pandey D, Bhunia A, Oh YJ, Chang F, Bergman Y, Kim JH, Serbo J, Boronina TN, Cole RN, Van Eyk J, Remaley AT, Berkowitz DE, Romer LH. OxLDL triggers retrograde translocation of arginase 2 in aortic endothelial cells via ROCK and mitochondrial processing peptidase. Circ Res. 2014 Aug 1;115(4):450-9. doi: 10.1161/CIRCRESAHA.115.304262.

51. Parodi-Rullán R, Sone JY, Fossati S. Endothelial Mitochondrial Dysfunction in Cerebral Amyloid Angiopathy and Alzheimer's Disease. J Alzheimers Dis. 2019;72(4):1019-1039. doi:10.3233/JAD-190357

52. Koo BH, Yi BG, Jeong MS, Kwon SH, Hoe KL, Kwon YG, Won MH, Kim YM, Ryoo S. Arginase II inhibition prevents interleukin-8 production through regulation of p38 MAPK phosphorylation activated by loss of mitochondrial membrane potential in nLDL-stimulated hAoSMCs. Exp Mol Med. 2018 Feb 2;50(2):e438. doi: 10.1038/emm.2017.254.

53. Pernow $\mathrm{J}$, Jung $\mathrm{C}$. Arginase as a potential target in the treatment of cardiovascular disease: reversal of arginine steal? Cardiovasc Res. 2013 Jun 1;98(3):334-43. doi: 10.1093/cvr/cvt036.

54. Polis B, Samson AO. Arginase as a Potential Target in the Treatment of Alzheimer's Disease. Adv Alzheimer's Dis. 2018;07(04):119-40. doi: 10.4236/aad.2018.74009. 
55. Liu P, Fleete MS, Jing Y, Collie ND, Curtis MA, Waldvogel HJ, Faull RL, Abraham WC, Zhang $\mathrm{H}$. Altered arginine metabolism in Alzheimer's disease brains. Neurobiol Aging. 2014 Sep;35(9):1992-2003. doi: 10.1016/j.neurobiolaging.2014.03.013.

56. Gueli MC, Taibi G. Alzheimer's disease: amino acid levels and brain metabolic status. Neurol Sci. 2013 Sep;34(9):1575-9. doi: 10.1007/s10072-013-1289-9.

57. Mangold U. The antizyme family: polyamines and beyond. IUBMB Life. 2005 Oct;57(10):671-6. doi: 10.1080/15216540500307031.

58. Matsufuji S, Matsufuji T, Miyazaki Y, Murakami Y, Atkins JF, Gesteland RF, Hayashi S. Autoregulatory frameshifting in decoding mammalian ornithine decarboxylase antizyme. Cell. 1995 Jan 13;80(1):51-60. doi: 10.1016/00928674(95)90450-6.

59. Rasila T, Lehtonen A, Kanerva K, Mäkitie LT, Haglund C, Andersson LC. Expression of ODC Antizyme Inhibitor 2 (AZIN2) in Human Secretory Cells and Tissues. PLoS One. 2016;11(3):e0151175. doi: 10.1371/journal.pone.0151175.

60. Mäkitie LT, Kanerva K, Polvikoski T, Paetau A, Andersson LC. Brain neurons express ornithine decarboxylase-activating antizyme inhibitor 2 with accumulation in Alzheimer's disease. Brain Pathol. 2010 May;20(3):571-80. doi: 10.1111/j.17503639.2009.00334.x.

61. Nilsson T, Bogdanovic N, Volkman I, Winblad B, Folkesson R, Benedikz E. Altered subcellular localization of ornithine decarboxylase in Alzheimer's disease brain. Biochem Biophys Res Commun. 2006 Jun 2;344(2):640-6. doi: 10.1016/j.bbrc.2006.03.191.

62. Pegg AE, Casero RA Jr. Current status of the polyamine research field. Methods Mol Biol. 2011;720:3-35. doi: 10.1007/978-1-61779-034-8_1.

63. Uemura T, Yerushalmi HF, Tsaprailis G, et al. Identification and characterization of a diamine exporter in colon epithelial cells. J Biol Chem. 2008;283(39):2642826435. doi:10.1074/jbc.M804714200 
64. Pegg AE. Spermidine/spermine-N(1)-acetyltransferase: a key metabolic regulator. Am J Physiol Endocrinol Metab. 2008 Jun;294(6):E995-1010. doi: 10.1152/ajpendo.90217.

65. Fernandez C, Sharrard RM, Talbot M, Reed BD, Monks N. Evaluation of the significance of polyamines and their oxidases in the aetiology of human cervical carcinoma. Br J Cancer. 1995 Nov;72(5):1194-9. doi: 10.1038/bjc.1995.485.

66. Feng Z, Hu W, Hu Y, Tang MS. Acrolein is a major cigarette-related lung cancer agent: Preferential binding at p53 mutational hotspots and inhibition of DNA repair. Proc Natl Acad Sci U S A. 2006 Oct 17;103(42):15404-9. doi: 10.1073/pnas.0607031103.

67. Saiki R, Nishimura K, Ishii I, Omura T, Okuyama S, Kashiwagi K, et al. Intense correlation between brain infarction and protein-conjugated acrolein. Stroke. 2009; 40:3356-3361. https://doi.org/10.1161/STROKEAHA.109.553248

68. Lovell MA, Xie C, Markesbery WR. Acrolein is increased in Alzheimer's disease brain and is toxic to primary hippocampal cultures. Neurobiol Aging. 2001 MarApr;22(2):187-94. doi: 10.1016/s0197-4580(00)00235-9.

69. Calingasan NY, Uchida K, Gibson GE. Protein-bound acrolein: a novel marker of oxidative stress in Alzheimer's disease. J Neurochem. 1999 Feb;72(2):751-6. doi: 10.1046/j.1471-4159.1999.0720751.x.

70. Dang TN, Arseneault M, Murthy V, Ramassamy C. Potential role of acrolein in neurodegeneration and in Alzheimer's disease. Curr Mol Pharmacol. 2010 Jun;3(2):66-78. PMID: 20302565.

71. Wood PL. Neurodegeneration and aldehyde load: from concept to therapeutics. J Psychiatry Neurosci. 2006 Sep;31(5):296-7. PMID: 16951732.

72. Wood PL, Khan MA, Moskal JR. The concept of "aldehyde load" in neurodegenerative mechanisms: Cytotoxicity of the polyamine degradation products hydrogen peroxide, acrolein, 3-aminopropanal, 3-acetamidopropanal and 4-aminobutanal in a retinal ganglion cell line. Brain research. 2007 May 
11;1145(1):150-156. https://doi.org/10.1016/j.brainres.2006.10.004

73. Masamichi T. On the melting temperature of nanoparticles. Bull Chem Soc Jpn. 1964;37(10):1514-22. https://doi.org/10.1246/bcsj.37.1514

74. Igarashi K, Sakamoto I, Goto N, Kashiwagi K, Honma R, Hirose S. Interaction between polyamines and nucleic acids or phospholipids. Arch Biochem Biophys. 1982 Dec;219(2):438-43. doi: 10.1016/0003-9861(82)90175-8. PMID: 6187285.

75. Watanabe S, Kusama-Eguchi K, Kobayashi H, Igarashi K. Estimation of polyamine binding to macromolecules and ATP in bovine lymphocytes and rat liver. J Biol Chem. 1991 Nov 5;266(31):20803-9. PMID: 1718969.

76. Muscari C, Guarnieri C, Stefanelli C, Giaccari A, Caldarera CM. Protective effect of spermine on DNA exposed to oxidative stress. Mol Cell Biochem. 1995 Mar 23;144(2):125-9. doi: 10.1007/BF00944391. PMID: 7623783.

77. Ha HC, Sirisoma NS, Kuppusamy P, Zweier JL, Woster PM, Casero RA Jr. The natural polyamine spermine functions directly as a free radical scavenger. Proc Natl Acad Sci U S A. 1998;95(19):11140-5. doi: 10.1073/pnas.95.19.11140.

78. Kanemura A, Yoshikawa Y, Fukuda W, Tsumoto K, Kenmotsu T, Yoshikawa K. Opposite effect of polyamines on In vitro gene expression: Enhancement at low concentrations but inhibition at high concentrations. PLoS One. 2018; 13(3):e0193595. doi:10.1371/journal.pone.0193595

79. Giannakouros T, Nikolakaki H, Georgatsos JG. Concentration-dependent effects of natural polyamines on peptide chain initiation and elongation in a cell-free system of protein synthesis. Mol Cell Biochem. 1990 Dec 3;99(1):9-19. doi: 10.1007/BF01261388. PMID: 2280767.

80. Xiao L, Swank RA, Matthews HR. Photoaffinity polyamines: sequence-specific interactions with DNA. Nucleic Acids Res. 1991;19(13):3701-3708. doi:10.1093/nar/19.13.3701

81. Marquet R, Houssier C. Different binding modes of spermine to A-T and G-C base pairs modulate the bending and stiffening of the DNA double helix. J Biomol 
Struct Dyn. 1988 Oct;6(2):235-46. doi: 10.1080/07391102.1988.10507710.

82. Ribeiro DA, Mello CF, Signor C, Rubin MA. Polyaminergic agents modulate the reconsolidation of conditioned fear. Neurobiol Learn Mem. 2013 Sep;104:9-15. doi: 10.1016/j.nlm.2013.04.008.

83. Signor C, Mello CF, Porto GP, Ribeiro DA, Rubin MA. Spermidine improves fear memory persistence. Eur J Pharmacol. 2014; 730:72-76. https://doi.org/10.1016/j.ejphar.2014.02.035.

84. Nichols CG, Lee S joo. Polyamines and potassium channels: A 25-year romance. Journal of Biological Chemistry. 2018; 293(48): 18779-88. https://doi.org/10.1074/jbc.TM118.003344.

85. Williams K. Interactions of polyamines with ion channels. Biochem J. 1997;325 ( Pt 2)(Pt 2):289-297. doi:10.1042/bj3250289

86. Baronas VA, Kurata HT. Inward rectifiers and their regulation by endogenous polyamines. Front Physiol. 2014;5:325. doi:10.3389/fphys.2014.00325

87. Williams K, Romano C, Molinoff PB. Effects of polyamines on the binding of [3H]MK-801 to the N-methyl-D-aspartate receptor: pharmacological evidence for the existence of a polyamine recognition site. Mol Pharmacol. 1989 Oct;36(4):575-81. PMID: 2554112.

88. Bowie D, Mayer ML. Inward rectification of both AMPA and kainate subtype glutamate receptors generated by polyamine-mediated ion channel block. Neuron. 1995 Aug;15(2):453-62. doi: 10.1016/0896-6273(95)90049-7.

89. Ferchmin PA, Pérez D, Biello M. Spermine is neuroprotective against anoxia and $\mathrm{N}$-methyl-D-aspartate in hippocampal slices. Brain Res. 2000 Mar 24;859(2):2739. doi: 10.1016/s0006-8993(00)01973-9.

90. Bell MR, Belarde JA, Johnson HF, Aizenman CD. A neuroprotective role for polyamines in a Xenopus tadpole model of epilepsy. Nat Neurosci. 2011 Apr;14(4):505-12. doi: 10.1038/nn.2777. 
91. Fiori LM, Turecki G. Implication of the polyamine system in mental disorders. J Psychiatry Neurosci. 2008 Mar;33(2):102-10. PMID: 18330456.

92. Chen GG, Fiori LM, Moquin L, Gratton A, Mamer O, Mechawar N, et al. Evidence of altered polyamine concentrations in cerebral cortex of suicide completers. Neuropsychopharmacology. 2010; 35, 1477-84. https://doi.org/10.1038/npp.2010.17.

93. Dempsey RJ, Maley BE, Cowen D, Olson JW. Ornithine decarboxylase activity and immunohistochemical location in postischemic brain. J Cereb Blood Flow Metab. 1988 Dec;8(6):843-7. doi: 10.1038/jcbfm.1988.141. PMID: 3192649.

94. Paschen W, Bengtsson F, Röhn G, Bonnekoh P, Siesjö B, Hossmann K -A. Cerebral Polyamine Metabolism in Reversible Hypoglycemia of Rat: Relationship to Energy Metabolites and Calcium. J Neurochem. 1991; 57: 204-215. https://doi.org/10.1111/j.1471-4159.1991.tb02117.x.

95. Sauer D, Martin P, Allegrini PR, Bernasconi R, Amacker H, Fagg GE. Differing effects of alpha-difluoromethylornithine and CGP 40116 on polyamine levels and infarct volume in a rat model of focal cerebral ischaemia. Neurosci Lett. $1992 \mathrm{Jul}$ 20;141(2):131-5. doi: 10.1016/0304-3940(92)90878-b. PMID: 1359466.

96. Halonen T, Sivenius J, Miettinen R, Halmekytö M, Kauppinen R, Sinervirta R, Alakuijala L, Alhonen L, MacDonald E, Jänne J, et al. Elevated seizure threshold and impaired spatial learning in transgenic mice with putrescine overproduction in the brain. Eur J Neurosci. 1993 Sep 1;5(9):1233-9. doi: 10.1111/j.14609568.1993.tb00978.x. PMID: 8281326.

97. Lukkarinen JA, Kauppinen RA, Gröhn OH, Oja JM, Sinervirta R, Järvinen A, Alhonen LI, Jänne J. Neuroprotective role of ornithine decarboxylase activation in transient focal cerebral ischaemia: a study using ornithine decarboxylaseoverexpressing transgenic rats. Eur J Neurosci. 1998 Jun;10(6):2046-55. doi: 10.1046/j.1460-9568.1998.00216.x. PMID: 9753092.

98. Raghavendra Rao VL, Dogan A, Bowen KK, Dempsey RJ. Ornithine 
decarboxylase knockdown exacerbates transient focal cerebral ischemia-induced neuronal damage in rat brain. J Cereb Blood Flow Metab. 2001 Aug;21(8):945-54. doi: 10.1097/00004647-200108000-00007. PMID: 11487730.

99. Gilad GM, Gilad VH. Polyamines can protect against ischemia-induced nerve cell death in gerbil forebrain. Exp Neurol. 1991 Mar;111(3):349-55. doi: 10.1016/00144886(91)90102-i. PMID: 1999235.

100. Morrison B 3rd, Pringle AK, McManus T, et al. L-arginyl-3,4-spermidine is neuroprotective in several in vitro models of neurodegeneration and in vivo ischaemia without suppressing synaptic transmission. $\mathrm{Br} \mathrm{J}$ Pharmacol. 2002;137(8):1255-1268. doi:10.1038/sj.bjp.0704986

101. Deng K, He H, Qiu J, Lorber B, Bryson JB, Filbin MT. Increased synthesis of spermidine as a result of upregulation of arginase I promotes axonal regeneration in culture and in vivo. J Neurosci. 2009;29(30):9545-9552. doi:10.1523/JNEUROSCI.1175-09.2009

102. Dhara M, Matta JA, Lei M, Knowland D, Yu H, Gu S, et al. Polyamine regulation of ion channel assembly and implications for nicotinic acetylcholine receptor pharmacology. Nat Commun. 2020; 11, 2799. https://doi.org/10.1038/s41467020-16629-3

103. Gotti C, Clementi F. Neuronal nicotinic receptors: from structure to pathology. Prog Neurobiol. 2004 Dec;74(6):363-96. doi: 10.1016/j.pneurobio.2004.09.006.

104. Anderson TR, Schanberg SM. Ornithine decarboxylase activity in developing rat brain. J Neurochem. 1972 Jun;19(6):1471-81. doi: 10.1111/j.14714159.1972.tb05090.x. PMID: 5035297.

105. Shaskan EG, Haraszti JH, Snyder SH. Polyamines: developmental alterations in regional disposition and metabolism in rat brain. J Neurochem. 1973 May; 20(5):1443-52. doi: 10.1111/j.1471-4159.1973.tb00256.x. PMID: 4716836.

106. Jasper TW, Luttge WG, Benton TB, Garnica AD. Polyamines in the developing mouse brain. Dev Neurosci. 1982;5(2-3):233-42. doi: 10.1159/000112681. 
107. Cayre M, Strambi C, Charpin P, Augier R, Strambi A. Specific requirement of putrescine for the mitogenic action of juvenile hormone on adult insect neuroblasts. Proc Natl Acad Sci U S A. 1997 Jul 22;94(15):8238-42. doi: 10.1073/pnas.94.15.8238.

108. Cayre M, Malaterre J, Strambi C, Charpin P, Ternaux JP, Strambi A. Short- and long-chain natural polyamines play specific roles in adult cricket neuroblast proliferation and neuron differentiation in vitro. J Neurobiol. $2001 \mathrm{Sep}$ 15;48(4):315-24. doi: 10.1002/neu.1060. PMID: 11500844.

109. Kilpeläinen P, Rybnikova E, Hietala O, Pelto-Huikko M. Expression of ODC and its regulatory protein antizyme in the adult rat brain. J Neurosci Res. 2000 Dec 1;62(5):675-85. doi: 10.1002/1097-4547(20001201)62:5<675::AIDJNR6>3.0.CO;2-S. PMID: 11104505.

110. Malaterre J, Strambi C, Aouane A, Strambi A, Rougon G, Cayre M. A novel role for polyamines in adult neurogenesis in rodent brain. Eur J Neurosci. 2004 Jul;20(2):317-30. doi: 10.1111/j.1460-9568.2004.03498.x. PMID: 15233741.

111. Halmekytö M, Hyttinen JM, Sinervirta R, Utriainen M, Myöhänen S, Voipio HM, Wahlfors J, Syrjänen S, Syrjänen K, Alhonen L, et al. Transgenic mice aberrantly expressing human ornithine decarboxylase gene. J Biol Chem. 1991 Oct 15;266(29):19746-51. PMID: 1717470.

112. Guerra GP, Rubin MA, Mello CF. Modulation of learning and memory by natural polyamines. Pharmacol Res. 2016;112:99-118. doi: 10.1016/j.phrs.2016.03.023.

113. de Vera N, Serratosa J, Artigas F, Martínez E. Toxic effects of putrescine in rat brain: Polyamines can be involved in the action of excitotoxins. Amino Acids. 1992 Oct;3(3):261-9. doi: 10.1007/BF00806001. PMID: 24193126.

114. De Sarro GB, Bagetta G, Spagnolo C, Nisticò G. Antagonists of N-methyl-Daspartate receptors block seizures induced by putrescine in the deep prepiriform cortex. Neuropharmacology. 1993 Jan;32(1):43-50. doi: 10.1016/00283908(93)90128-p. PMID: 8429916. 
115. Sparapani M, Dall'Olio R, Gandolfi O, Ciani E, Contestabile A. Neurotoxicity of polyamines and pharmacological neuroprotection in cultures of rat cerebellar granule cells. Exp Neurol. 1997 Nov;148(1):157-66. doi: 10.1006/exnr.1997.6627.

116. de Vera N, Martínez E, Sanfeliu C. Spermine induces cell death in cultured human embryonic cerebral cortical neurons through N-methyl-D-aspartate receptor activation. J Neurosci Res. 2008;86(4):861-72. doi: 10.1002/jnr.21538.

117. Agnati LF, Fuxe K, Davalli P, Zini I, Corti A, Zoli M. Striatal ornithine decarboxylase activity following neurotoxic and mechanical lesions of the mesostriatal dopamine system of the male rat. Acta Physiol Scand. 1985 Sep;125(1):173-5. doi: 10.1111/j.1748-1716.1985.tb07704.x. PMID: 4050488.

118. Agnati LF, Fuxe K, Zoli M, Davalli P, Corti A, Zini I, Toffano G. Effects of neurotoxic and mechanical lesions of the mesostriatal dopamine pathway on striatal polyamine levels in the rat: modulation by chronic ganglioside GM1 treatment. Neurosci Lett. 1985 Nov 11;61(3):339-44. doi: 10.1016/03043940(85)90487-2. PMID: 3935984.

119. Baudry M, Lynch G, Gall C. Induction of ornithine decarboxylase as a possible mediator of seizure-elicited changes in genomic expression in rat hippocampus. $\mathrm{J}$ Neurosci. 1986 Dec;6(12):3430-5. doi: 10.1523/JNEUROSCI.06-12-03430.

120. Koenig $\mathrm{H}$, Goldstone AD, Lu CY. Blood-brain barrier breakdown in cold-injured brain is linked to a biphasic stimulation of ornithine decarboxylase activity and polyamine synthesis: both are coordinately inhibited by verapamil, dexamethasone, and aspirin. J Neurochem. 1989 Jan;52(1):101-9. doi: 10.1111/j.1471-4159.1989.tb10903.x. PMID: 2491756.

121. de Vera N, Artigas F, Serratosa J, Martínez E. Changes in polyamine levels in rat brain after systemic kainic acid administration: relationship to convulsant activity and brain damage. J Neurochem. 1991 Jul;57(1):1-8. doi: 10.1111/j.14714159.1991.tb02091.x. PMID: 2051159.

122. Sabatini DM. Twenty-five years of mTOR: Uncovering the link from nutrients to 
growth. Proc Natl Acad Sci U S A. 2017 Nov 7;114(45):11818-11825. doi: 10.1073/pnas. 1716173114 .

123. Lipton JO, Sahin M. The neurology of mTOR. Neuron. 2014 Oct 22;84(2):275-91. doi: 10.1016/j.neuron.2014.09.034.

124. Li X, Alafuzoff I, Soininen H, Winblad B, Pei JJ. Levels of mTOR and its downstream targets 4E-BP1, eEF2, and eEF2 kinase in relationships with tau in Alzheimer's disease brain. FEBS J. 2005 Aug;272(16):4211-20. doi: 10.1111/j.1742-4658.2005.04833.x. PMID: 16098202.

125. Yepuri G, Velagapudi S, Xiong Y, Rajapakse AG, Montani JP, Ming XF, Yang Z. Positive crosstalk between arginase-II and S6K1 in vascular endothelial inflammation and aging. Aging Cell. 2012 Dec;11(6):1005-16. doi: 10.1111/acel.12001.

126. Xiong Y, Yepuri G, Montani JP, Ming XF, Yang Z. Arginase-II Deficiency Extends Lifespan in Mice. Front Physiol. 2017; 8:682. doi: 10.3389/fphys.2017.00682.

127. Kaeberlein M. Targeting mTOR signaling to promote healthy longevity. FASEB J. 2017; 31: 256.4-256.4. https://doi.org/10.1096/fasebj.31.1_supplement.256.4

128. Talboom JS, Velazquez $\mathrm{R}$, Oddo $\mathrm{S}$. The mammalian target of rapamycin at the crossroad between cognitive aging and Alzheimer's disease. NPJ Aging Mech Dis. 2015 Oct 15;1:15008. doi: 10.1038/npjamd.2015.8.

129. Tramutola A, Triplett JC, Di Domenico F, Niedowicz DM, Murphy MP, Coccia R, Perluigi M, Butterfield DA. Alteration of mTOR signaling occurs early in the progression of Alzheimer disease (AD): analysis of brain from subjects with preclinical $A D$, amnestic mild cognitive impairment and late-stage AD. J Neurochem. 2015 Jun;133(5):739-49. doi: 10.1111/jnc. 13037.

130. Spilman P, Podlutskaya N, Hart MJ, Debnath J, Gorostiza O, Bredesen D, Richardson A, Strong R, Galvan V. Inhibition of mTOR by rapamycin abolishes cognitive deficits and reduces amyloid-beta levels in a mouse model of Alzheimer's disease. PLoS One. 2010 Apr 1;5(4):e9979. doi: 
10.1371/journal.pone.0009979.

131. Caccamo A, Branca C, Talboom JS, Shaw DM, Turner D, Ma L, Messina A, Huang Z, Wu J, Oddo S. Reducing Ribosomal Protein S6 Kinase 1 Expression Improves Spatial Memory and Synaptic Plasticity in a Mouse Model of Alzheimer's Disease. J Neurosci. 2015 Oct 14;35(41):14042-56. doi:

10.1523/JNEUROSCI.2781-15.2015.

132. Kim YM, Jung $\mathrm{CH}$, Seo $\mathrm{M}$, et al. mTORC1 phosphorylates UVRAG to negatively regulate autophagosome and endosome maturation. Mol Cell. 2015;57(2):207218. doi:10.1016/j.molcel.2014.11.013

133. Mizushima N, Komatsu M. Autophagy: renovation of cells and tissues. Cell. 2011 Nov 11;147(4):728-41. doi: 10.1016/j.cell.2011.10.026. PMID: 22078875.

134. Nixon RA, Yang DS, Lee JH. Neurodegenerative lysosomal disorders: a continuum from development to late age. Autophagy. 2008 Jul;4(5):590-9. doi: 10.4161/auto.6259.

135. Nixon RA. Autophagy, amyloidogenesis and Alzheimer disease. J Cell Sci. 2007 Dec 1;120(Pt 23):4081-91. doi: 10.1242/jcs.019265. PMID: 18032783.

136. Xiong $Y$, Yepuri G, Forbiteh M, et al. ARG2 impairs endothelial autophagy through regulation of MTOR and PRKAA/AMPK signaling in advanced atherosclerosis. Autophagy. 2014;10(12):2223-2238. doi:10.4161/15548627.2014.981789

137. Yang Z, Ming XF. Arginase: the emerging therapeutic target for vascular oxidative stress and inflammation. Front Immunol. 2013;4:149.

doi:10.3389/fimmu.2013.00149

138. Yu Y, Xiong Y, Montani JP, Yang Z, Ming XF. Arginase-II activates mTORC1 through myosin-1b in vascular cell senescence and apoptosis. Cell Death Dis. 2018; 9, 313. https://doi.org/10.1038/s41419-018-0356-9

139. Polis B, Samson A. A New Perspective on Alzheimer's Disease as a Brain Expression of a Complex Metabolic Disorder. In: Wisniewski T, editor. Alzheimer's Disease. Brisbane; 2019. p. 1-22. doi: 10.15586/alzheimersdisease.2019.ch1 
140. Bernstein HG, Müller M. Increased immunostaining for L-ornithine decarboxylase occurs in neocortical neurons of Alzheimer's disease patients. Neurosci Lett. 1995 Feb 17;186(2-3):123-6. doi: 10.1016/0304-3940(95)11301-c. PMID: 7777179.

141. Morrison LD, Kish SJ. Brain polyamine levels are altered in Alzheimer's disease. Neurosci Lett. 1995 Sep 1;197(1):5-8. doi: 10.1016/0304-3940(95)11881-v.

142. Morrison LD, Cao XC, Kish SJ. Ornithine decarboxylase in human brain: influence of aging, regional distribution, and Alzheimer's disease. J Neurochem. 1998 Jul;71(1):288-94. doi: 10.1046/j.1471-4159.1998.71010288.x. PMID: 9648877.

143. Yatin SM, Yatin M, Aulick T, Ain KB, Butterfield DA. Alzheimer's amyloid betapeptide associated free radicals increase rat embryonic neuronal polyamine uptake and ornithine decarboxylase activity: protective effect of vitamin $\mathrm{E}$. Neurosci Lett. 1999 Mar 19;263(1):17-20. doi: 10.1016/s0304-3940(99)00101-9.

144. Yatin SM, Yatin M, Varadarajan S, Ain KB, Butterfield DA. Role of spermine in amyloid beta-peptide-associated free radical-induced neurotoxicity. J Neurosci Res. 2001 Mar 1;63(5):395-401. doi: 10.1002/10974547(20010301)63:5<395::AID-JNR1034>3.0.CO;2-Q. PMID: 11223914.

145. Kindy MS, Hu Y, Dempsey RJ. Blockade of ornithine decarboxylase enzyme protects against ischemic brain damage. J Cereb Blood Flow Metab. 1994 Nov;14(6):1040-5. doi: 10.1038/jcbfm.1994.136. PMID: 7929646.

146. Chen H, Yoshioka H, Kim GS, Jung JE, Okami N, Sakata H, Maier CM, Narasimhan P, Goeders CE, Chan PH. Oxidative stress in ischemic brain damage: mechanisms of cell death and potential molecular targets for neuroprotection. Antioxid Redox Signal. 2011 Apr 15;14(8):1505-17. doi: 10.1089/ars.2010.3576.

147. Alber J, McGarry K, Noto RB, Snyder PJ. Use of Eflornithine (DFMO) in the Treatment of Early Alzheimer's Disease: A Compassionate Use, Single-Case Study. Front Aging Neurosci. 2018 Mar 6;10:60. doi: 10.3389/fnagi.2018.00060.

148. Sandusky-Beltran LA, Kovalenko A, Ma C, Calahatian JIT, Placides DS, Watler 
MD, et al. Spermidine/spermine-N 1-acetyltransferase ablation impacts tauopathy-induced polyamine stress response. Alzheimer's Res Ther. 2019;11(1):1-24. doi: 10.1186/s13195-019-0507-y.

149. Zheng L, Cedazo-Minguez A, Hallbeck M, Jerhammar F, Marcusson J, Terman A. Intracellular distribution of amyloid beta peptide and its relationship to the lysosomal system. Transl Neurodegener. 2012 Sep 26;1(1):19. doi: 10.1186/2047-9158-1-19.

150. Hansmannel F, Sillaire A, Kamboh MI, Lendon C, Pasquier F, Hannequin D, Laumet G, Mounier A, Ayral AM, DeKosky ST, Hauw JJ, Berr C, Mann D, Amouyel $\mathrm{P}$, Campion D, Lambert JC. Is the urea cycle involved in Alzheimer's disease? J Alzheimers Dis. 2010;21(3):1013-21. doi: 10.3233/JAD-2010-100630.

151. Xu J, Begley P, Church SJ, Patassini S, Hollywood KA, Jüllig M, Curtis MA, Waldvogel HJ, Faull RL, Unwin RD, Cooper GJ. Graded perturbations of metabolism in multiple regions of human brain in Alzheimer's disease: Snapshot of a pervasive metabolic disorder. Biochim Biophys Acta. 2016 Jun;1862(6):108492. doi: 10.1016/j.bbadis.2016.03.001.

152. Liu P, Fleete MS, Jing $Y$, Collie ND, Curtis MA, Waldvogel HJ, Faull RL, Abraham WC, Zhang H. Altered arginine metabolism in Alzheimer's disease brains. Neurobiol Aging. 2014 Sep;35(9):1992-2003. doi: 10.1016/j.neurobiolaging.2014.03.013.

153. Mahajan UV, Varma VR, Griswold ME, Blackshear CT, An Y, Oommen AM, Varma S, Troncoso JC, Pletnikova O, O'Brien R, Hohman TJ, Legido-Quigley C, Thambisetty M. Dysregulation of multiple metabolic networks related to brain transmethylation and polyamine pathways in Alzheimer disease: A targeted metabolomic and transcriptomic study. PLoS Med. 2020 Jan 24;17(1):e1003012. doi: 10.1371/journal.pmed.1003012.

154. Fonteh AN, Harrington RJ, Tsai A, Liao P, Harrington MG. Free amino acid and dipeptide changes in the body fluids from Alzheimer's disease subjects. Amino Acids. 2007 Feb;32(2):213-24. doi: 10.1007/s00726-006-0409-8. 
155. Ibáñez C, Simó C, Martín-Álvarez PJ, Kivipelto M, Winblad B, Cedazo-Mínguez A, Cifuentes A. Toward a predictive model of Alzheimer's disease progression using capillary electrophoresis-mass spectrometry metabolomics. Anal Chem. 2012 Oct 16;84(20):8532-40. doi: 10.1021/ac301243k.

156. Zhang YQ, Tang YB, Dammer E, Liu JR, Zhao YW, Zhu L, Ren RJ, Chen HZ, Wang G, Cheng Q. Dysregulated Urinary Arginine Metabolism in Older Adults With Amnestic Mild Cognitive Impairment. Front Aging Neurosci. 2019 Apr 24;11:90. doi: 10.3389/fnagi.2019.00090.

157. Graham SF, Chevallier OP, Elliott CT, Hölscher C, Johnston J, McGuinness B, Kehoe PG, Passmore AP, Green BD. Untargeted metabolomic analysis of human plasma indicates differentially affected polyamine and L-arginine metabolism in mild cognitive impairment subjects converting to Alzheimer's disease. PLoS One. 2015 Mar 24;10(3):e0119452. doi: 10.1371/journal.pone.0119452.

158. Hu J, Mahmoud Ml, el-Fakahany EE. Polyamines inhibit nitric oxide synthase in rat cerebellum. Neurosci Lett. 1994 Jul 4;175(1-2):41-5. doi: 10.1016/03043940(94)91073-1. PMID: 7526294.

159. Zarifkar A, Choopani S, Ghasemi R, Naghdi N, Maghsoudi AH, Maghsoudi N, Rastegar K, Moosavi M. Agmatine prevents LPS-induced spatial memory impairment and hippocampal apoptosis. Eur J Pharmacol. 2010;634(1-3):84-8. doi: 10.1016/j.ejphar.2010.02.029.

160. Ming XF, Rajapakse AG, Carvas JM, Ruffieux J, Yang Z. Inhibition of S6K1 accounts partially for the anti-inflammatory effects of the arginase inhibitor Lnorvaline. BMC Cardiovasc Disord. 2009;9:12. doi: 10.1186/1471-2261-9-12.

161. Polis B, Srikanth KD, Gurevich V, Gil-Henn H, Samson AO. L-Norvaline, a new therapeutic agent against Alzheimer's disease. Neural Regen Res. 2019 Sep;14(9):1562-1572. doi: 10.4103/1673-5374.255980. PMID: 31089055.

162. Polis B, Gurevich V, Assa M, Samson AO. Norvaline Restores the BBB Integrity in a Mouse Model of Alzheimer's Disease. Int J Mol Sci. 2019 Sep 
18;20(18):4616. doi: 10.3390/ijms20184616. PMID: 31540372.

163. Polis B, Srikanth KD, Gurevich V, Bloch N, Gil-Henn H, Samson AO. Arginase Inhibition Supports Survival and Differentiation of Neuronal Precursors in Adult Alzheimer's Disease Mice. Int J Mol Sci. 2020 Feb 8;21(3):1133. doi: 10.3390/ijms21031133. PMID: 32046281.

164. Yang Q, Wei J, Zhong L, Shi M, Zhou P, Zuo S, Wu K, Zhu M, Huang X, Yu Y, Zhang $\mathrm{H}$, Yin H, Zhou J. Cross talk between histone deacetylase 4 and STAT6 in the transcriptional regulation of arginase 1 during mouse dendritic cell differentiation. Mol Cell Biol. 2015 Jan;35(1):63-75. doi: 10.1128/MCB.00805-14.

165. Yang $S$ shuang, Zhang $R$, Wang G, Zhang $Y$ fang. The development prospection of HDAC inhibitors as a potential therapeutic direction in Alzheimer's disease. Transl Neurodegener. 2017; 6, 19. https://doi.org/10.1186/s40035-017-0089-1

166. Martínez-González K, Garcia-delaTorre L, Almeida-Gutiérrez E, Flores-Chavez S, Mejía-Aranguré JM, Garcia-delaTorre P. Citrulline supplementation improves spatial memory in a murine model for Alzheimer's disease. bioRxiv. 2020.06.15.153346; doi: https://doi.org/10.1101/2020.06.15.153346

167. Hunt JB Jr, Nash KR, Placides D, Moran P, Selenica ML et al. Sustained Arginase 1 Expression Modulates Pathological Tau Deposits in a Mouse Model of Tauopathy. J Neurosci. 2015 Nov 4;35(44):14842-60. doi:

10.1523/JNEUROSCI.3959-14.2015.

168. Ma C, Hunt JB, Selenica MB, et al. Arginase 1 Insufficiency Precipitates Amyloid$\beta$ Deposition and Hastens Behavioral Impairment in a Mouse Model of Amyloidosis. Front Immunol. 2021;11:582998. doi:10.3389/fimmu.2020.582998

169. Ramsden M, Kotilinek L, Forster C, Paulson J, McGowan E, SantaCruz K, Guimaraes A, Yue M, Lewis J, Carlson G, Hutton M, Ashe KH. Age-dependent neurofibrillary tangle formation, neuron loss, and memory impairment in a mouse model of human tauopathy (P301L). J Neurosci. 2005 Nov 16;25(46):10637-47. doi: 10.1523/JNEUROSCI.3279-05.2005. 
170. Patel C, Xu Z, Shosha E, et al. Treatment with polyamine oxidase inhibitor reduces microglial activation and limits vascular injury in ischemic retinopathy. Biochim Biophys Acta. 2016;1862(9):1628-1639.

doi:10.1016/j.bbadis.2016.05.020

171. Pichavaram P, Palani CD, Patel C, Xu Z, Shosha E, Fouda AY, Caldwell RB, Narayanan SP. Targeting Polyamine Oxidase to Prevent Excitotoxicity-Induced Retinal Neurodegeneration. Front Neurosci. 2019 Jan 10;12:956. doi: 10.3389/fnins.2018.00956.

172. Angelucci E, Moreno S, D'Amelio M, et al. A new transgenic mouse model for studying the neurotoxicity of spermine oxidase dosage in the response to excitotoxic injury. Mol Neurodegener. 2013;8(Suppl 1):P4. doi:10.1186/17501326-8-S1-P4

173. Vingtdeux V, Giliberto L, Zhao H, Chandakkar P, Wu Q, Simon JE, Janle EM, Lobo J, Ferruzzi MG, Davies P, Marambaud P. AMP-activated protein kinase signaling activation by resveratrol modulates amyloid-beta peptide metabolism. J Biol Chem. 2010 Mar 19;285(12):9100-13. doi: 10.1074/jbc.M109.060061.

174. Cui CM, Gao JL, Cui Y, Sun LQ, Wang YC, Wang KJ, Li R, Tian YX, Cui JZ. Chloroquine exerts neuroprotection following traumatic brain injury via suppression of inflammation and neuronal autophagic death. Mol Med Rep. 2015 Aug;12(2):2323-8. doi: 10.3892/mmr.2015.3611 .

175. Yabuki Y, Shioda N, Yamamoto Y, Shigano M, Kumagai K, Morita M, Fukunaga $\mathrm{K}$. Oral L-citrulline administration improves memory deficits following transient brain ischemia through cerebrovascular protection. Brain Res. $2013 \mathrm{Jul}$ 3;1520:157-67. doi: 10.1016/j.brainres.2013.05.011.

176. Narayanan SP, Xu Z, Putluri N, Sreekumar A, Lemtalsi T, Caldwell RW, et al. Arginase 2 deficiency reduces hyperoxia-mediated retinal neurodegeneration through the regulation of polyamine metabolism. Cell Death Dis. 2014;5(2). https://doi.org/10.1038/cddis.2014.23 
177. Dong X, Tan NB, Howell KB, Barresi S, Freeman JL, Vecchio D, et al. Bi-allelic LoF NRROS Variants Impairing Active TGF- $\beta 1$ Delivery Cause a Severe InfantileOnset Neurodegenerative Condition with Intracranial Calcification. Am J Hum Genet. 2020 Apr 2;106(4):559-569. doi: 10.1016/j.ajhg.2020.02.014.

178. Prelich G. Gene overexpression: uses, mechanisms, and interpretation. Genetics. 2012 Mar;190(3):841-54. doi: 10.1534/genetics.111.136911.

179. Nelson NC. A Knockout Experiment: Disciplinary Divides and Experimental Skill in Animal Behaviour Genetics. Med Hist. 2015 Jul;59(3):465-85. doi: 10.1017/mdh.2015.30. PMID: 26090739.

180. Routtenberg A. Knockout mouse fault lines. Nature. 1995 Mar 23;374(6520):3145. doi: 10.1038/374314b0. PMID: 7885468.

181. Hughes KA, Reynolds RM. Evolutionary and mechanistic theories of aging. Annu Rev Entomol. 2005;50:421-45. doi: 10.1146/annurev.ento.50.071803.130409.

182. Terry RD, Katzman R. Life span and synapses: will there be a primary senile dementia? Neurobiol Aging. 2001;22(3):347-8. doi: 10.1016/s01974580(00)00250-5. PMID: 11378236.

183. Williams GC. Pleiotropy, Natural Selection, and the Evolution of Senescence. Evolution (N Y). 1957; 11: 398-411. https://doi.org/10.1111/j.15585646.1957.tb02911.x

184. Bufill E, Blesa R, Augustí J. Alzheimer's disease: an evolutionary approach. J Anthropol Sci. 2013;91:135-57. doi: 10.4436/jass.91001.

185. Fox M. 'Evolutionary medicine' perspectives on Alzheimer's Disease: Review and new directions. Ageing Res Rev. 2018 Nov;47:140-148. doi: 10.1016/j.arr.2018.07.008.

186. Naj AC, Jun G, Reitz C, Kunkle BW, Perry W, Park YS, et al. Effects of multiple genetic loci on age at onset in late-onset Alzheimer disease: A genome-wide association study. JAMA Neurol. 2014 Nov;71(11):1394-404. doi: 10.1001/jamaneurol.2014.1491. 
187. Tuminello ER, Han SD. The apolipoprotein e antagonistic pleiotropy hypothesis: review and recommendations. Int J Alzheimers Dis. 2011 Feb 24;2011:726197. doi: 10.4061/2011/726197. PMID: 21423560.

188. Glass DJ, Arnold SE. Some evolutionary perspectives on Alzheimer's disease pathogenesis and pathology. Alzheimers Dement. 2012 Jul;8(4):343-51. doi: 10.1016/j.jalz.2011.05.2408.

189. Madeo F, Eisenberg T, Pietrocola F, Kroemer G. Spermidine in health and disease. Science. 2018 Jan 26;359(6374):eaan2788. doi: 10.1126/science.aan2788. PMID: 29371440.

190. Duffy PE, Kremzner LT. Ornithine decarboxylase activity and polyamines in relation to aging of human fibroblasts. Exp Cell Res. 1977 Sep;108(2):435-40. doi: 10.1016/s0014-4827(77)80052-9. PMID: 891650.

191. Beyer HS, Ellefson M, Sherman R, Zieve L. Aging alters ornithine decarboxylase and decreases polyamines in regenerating rat liver but putrescine replacement has no effect. J Lab Clin Med. 1992 Jan;119(1):38-47. PMID: 1727906.

192. Lin IH, Chang JL, Hua K, Huang WC, Hsu MT, Chen YF. Skeletal muscle in aged mice reveals extensive transformation of muscle gene expression. BMC Genet. 2018 Aug 8;19(1):55. doi: 10.1186/s12863-018-0660-5.

193. Eisenberg T, Knauer H, Schauer A, Büttner S, Ruckenstuhl C, Carmona-Gutierrez $\mathrm{D}$, et al. Induction of autophagy by spermidine promotes longevity. Nat Cell Biol. 2009 Nov;11(11):1305-14. doi: 10.1038/ncb1975.

194. Pandya CD, Lee B, Toque HA, Mendhe B, Bragg RT, Pandya B, Atawia RT, Isales C, Hamrick M, Caldwell RW, Fulzele S. Age-Dependent Oxidative Stress Elevates Arginase 1 and Uncoupled Nitric Oxide Synthesis in Skeletal Muscle of Aged Mice. Oxid Med Cell Longev. 2019 May 8;2019:1704650. doi: $10.1155 / 2019 / 1704650$.

195. Santhanam L, Christianson DW, Nyhan D, Berkowitz DE. Arginase and vascular aging. J Appl Physiol. 2008 Nov;105(5):1632-42. doi: 
10.1152/japplphysiol.90627.2008.

196. Gilinsky MA, Polityko YK, Markel AL, Latysheva TV, Samson AO, Polis B, Naumenko SE. Norvaline Reduces Blood Pressure and Induces Diuresis in Rats with Inherited Stress-Induced Arterial Hypertension. Biomed Res Int. 2020 Feb 12;2020:4935386. doi: 10.1155/2020/4935386. PMID: 32149110.

197. Kashyap SR, Lara A, Zhang R, Park YM, DeFronzo RA. Insulin reduces plasma arginase activity in type 2 diabetic patients. Diabetes Care. 2008 Jan;31(1):134-9. doi: $10.2337 / \mathrm{dc} 07-1198$.

\section{Acknowledgements}

We would like to thank Dr. Naamah Bloch for critical reading and valuable advice. Figures were created with BioRender.com. 